\section{Surgical Complications of Childhood Tumors}

G. Suren Arul, Richard D. Spicer

Contents

22.1 Rare Surgical Presentations

of Cancer in Childhood . . . . . . . . . . . . . . 497

22.2 Soft Tissue Complications . . . . . . . . . . . . . 497

22.2 .1 Cellulitis . . . . . . . . . . . . . . . . . . 498

22.2.2 Superficial Abscesses . . . . . . . . . . . . . . 498

22.2.3 Radiation Necrosis . . . . . . . . . . . . . . . . 498

22.2.4 Necrotizing Fasciitis . . . . . . . . . . . . . . 498

22.2.5 Compartment Syndrome . . . . . . . . . . . 499

22.3 Thoracic Complications . . . . . . . . . . . . 499

22.3.1 Superior Vena Caval Syndrome . . . . . . . . . . 500

22.3.2 Superior Mediastinal Syndrome . . . . . . . . 500

22.3.3 Pneumomediastinum, Pneumopericardium, and Surgical Emphysema _. . . . . . . . . . . . . 500

22.3.4 Cardiac Tamponade . . . . . . . . . . . . 500

22.3.5 Pleurodesis . . . . . . . . . . . . . . . . 500

22.3.6 Fungal Lung Lesions . . . . . . . . . . . . . . . 500

22.3.7 Complications of Long Lines _. . . . . . . . . 500

22.3.8 Complications of Catheter Removal . . . . . . . 501

22.4 Gastrointestinal Complications . . . . . . . 502

22.4.1 Acute Abdominal Pain . . . . . . . . . . . . . 502

22.4.1.1 Overview . . . . . . . . . . . . . . . . 502

22.4.1.2 The Role of Diagnostic Imaging . . . . . . . . . . . 502

22.4.1.3 The Role of Endoscopy . . . . . . . . . . . . . . 502

22.4.1.4 Assessment of Acute Abdominal Pain

in the Child with Malignant Disease . . . . . . . . 503

22.4.1.5 Metabolic Causesof the Acute Abdomen . . . . . . 503

22.4.2 Specific Causes of Abdominal Pain . . . . . . 503

22.4.2.1 Intestinal Obstruction. . . . . . . . . . . . . . 503

22.4.2.2 Radiation Enteritis. . . . . . . . . . . . . 503

22.4.2.3 Treatment of Obstruction

in the Terminally Ill Child . . . . . . . . . . . . . . . . . 505

22.4.2.4 Neutropenic Enterocolitis . . . . . . . . . . . . 505

22.4.2.5 Pancreatitis . . . . . . . . . . . . . . . . . 506

22.4.2.6 Cholecystitis . . . . . . . . . . . . . . . . . . 507

22.4.2.7 Ruptured Tumor . . . . . . . . . . . . . . . . . . . 507

22.4.3 Gastrointestinal Bleeding . . . . . . . . . . . 507

22.4.3.1 The Role of Diagnostic Imaging in Acute Gastrointestinal Bleeding . . . . . . . . 508

22.4.3.2 The Role of Endoscopy in Acute Gastrointestinal Bleeding . . . . . . . . . 508

22.4.3.3 Algorithm for Management of Gastrointestinal Bleeding . . . . . . . . . . . 508

22.4.3.4 Esophagitis in the Immunosuppressed Patient . . 508

22.4.3.5 Infectious Colitis. . . . . . . . . . . . . . . . 508

22.4.4 Perianal Lesions . . . . . . . . . . . . 510

22.5 Genitourinary Tract Complications . . . . . . 511
22.5.1 Hemorrhagic Cystitis . . . . . . . . . . 511

22.5.1.1 Incidence . . . . . . . . . . . . . . . . . . . . . . 511

22.5.1.2 Clinical Features . . . . . . . . . . . . . . . . 511

22.5.1.3 Diagnosis . . . . . . . . . . . . . . . . . . . . . . . . 511

22.5.1.4 Prevention. . . . . . . . . . . . . . . . 511

22.5.1.5 Treatment. . . . . . . . . . . . . . . . . 512

22.5.1.6 Outcome. . . . . . . . . . . . . . . 513

22.5.1.7 Other Conditions Affecting

the Genitourinary Tract. . . . . . . . . . . . . . 514

$22.6 \quad$ Intestinal Graft-Versus-Host Disease . . . . . 514

22.6.1 Clinical Features . . . . . . . . . . . . . . . . . . . . . . 514

22.6 .2 Investigations . . . . . . . . . . . . 515

22.6.3 Other Problems

22.6.4 Treatment . . . . . . . . . . . . . 515

References . . . . . . . . . . . . . . . . . 516

\subsection{Rare Surgical Presentations of Cancer in Childhood}

Most childhood tumors will first present to a physician; some tumors will present in an atypical manner and may mimic a surgical condition. The diagnosis may be missed if the surgeon is not aware of the possibility of cancer. A very great number of rare presentations of childhood cancer have been described in the literature. It is important that the surgeon who is not experienced in the management of childhood cancer is aware that an apparently benign condition could be a manifestation of an underlying malignancy [71, 83] (Table 22.1).

\subsection{Soft Tissue Complications}

Soft tissue problems are a common cause for surgical consultation on the oncology ward. Immunosuppression, steroid-induced skin changes, and prolonged immobilization all contribute to skin infections. These may start as simple localized infections, which may quickly spread into life-threatening problems. Although the conditions outlined below are all related, they do have significant differences, which are reflected 
Table 22.1 Surgical presentation of tumors

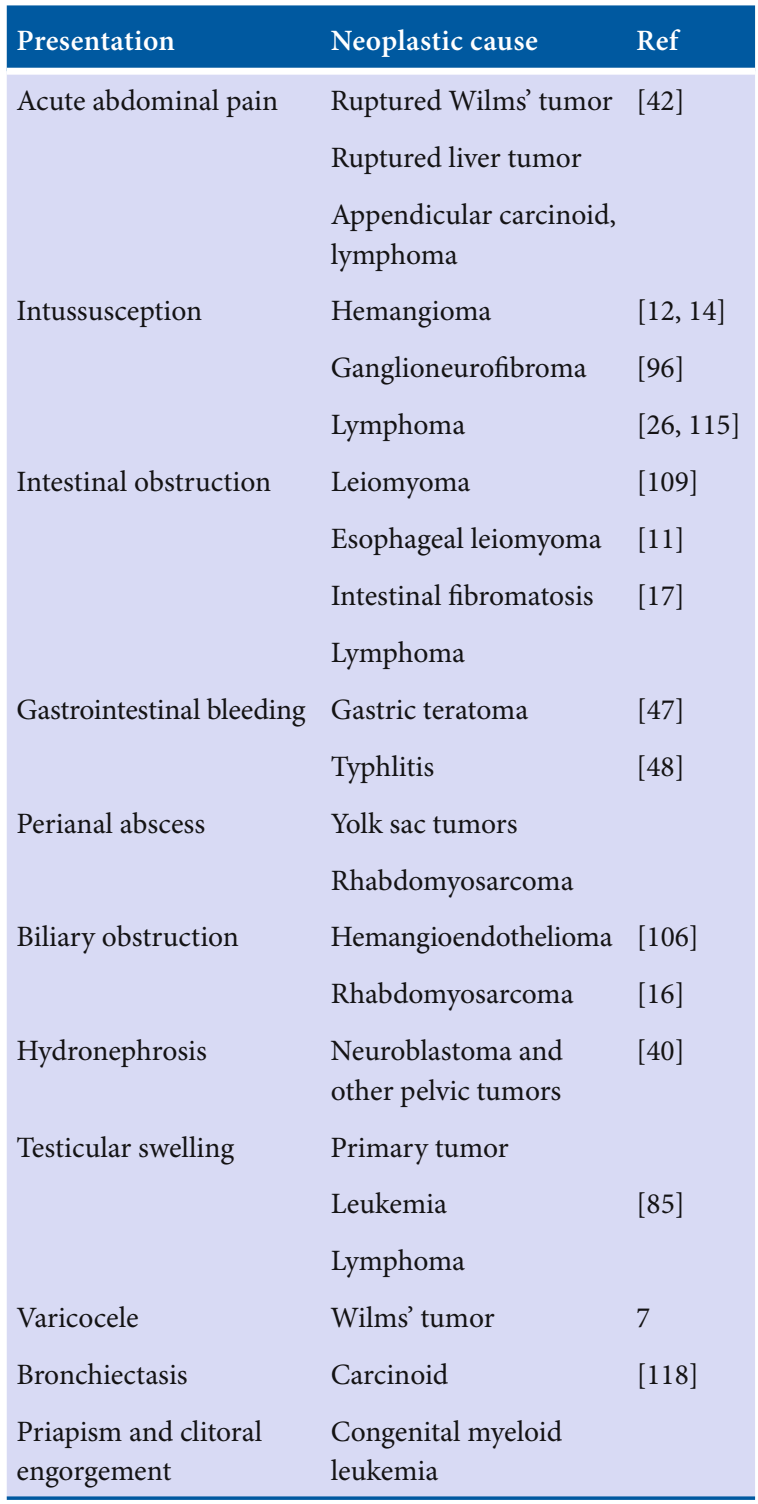

in their varying management. Careful clinical diagnosis in conjunction with relevant microbiological, hematological, and biochemical findings is essential.

\subsubsection{Cellulitis}

Usually soft tissue problems involve no more than simple local infections. However, as these children are often immunosuppressed, a localized infection can quickly spread to a life-threatening cellulitis. Any areas of erythema should be treated suspiciously with swabs of the area and blood cultures being sent. Antibiotics should be employed early in a suspected infection.
Proven cellulitis should be managed by marking the area of erythema so that any progress can be monitored. Intravenous antibiotics are mandatory and should be prescribed after discussion with the infectious disease specialists.

\subsubsection{Superficial Abscesses}

Conditions such as paronychia and superficial skin abscesses in the groin or axilla are relatively common. In patients with a normal neutrophil count the treatment of choice is incision and drainage of the area of maximum fluctuation. In the cases of neutropenic patients most abscesses will not contain pus but watery fluid containing no neutrophils. These instances are best treated with antibiotics and granulocyte stimulating factor; any areas of fluctuation can be aspirated with a fine needle to provide fluid for culture and sensitivity testing often without the need for incision and drainage.

\subsubsection{Radiation Necrosis}

Children receiving radiotherapy may develop extensive erythema of the skin and skin necrosis. This was seen more commonly in treatment protocols that advocated large doses of radiation therapy to superficial areas in the body. This is no longer the case with current protocols (Fig. 22.1).

\subsubsection{Necrotizing Fasciitis}

Established cellulitis may progress to necrotizing fasciitis. The common forms of this disease are either

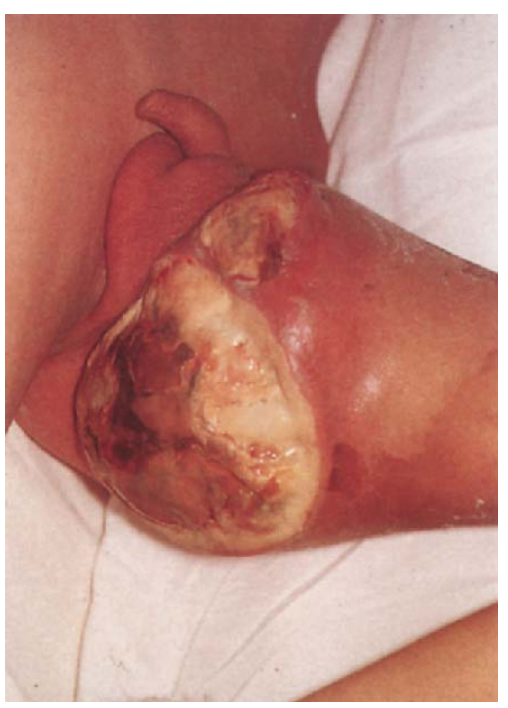

Fig. 22.1 Skin necrosis after chemotherapy and radiotherapy to shrink a rhabdomyosarcoma of the thigh. 
caused by group A streptococcus or a mixed flora of anaerobic and aerobic bacteria. This later condition is known as Fournier's gangrene if it occurs around the perineum or Meleney's gangrene if it occurs on the abdominal wall (often associated with a recent operation wound).

In this condition the patient is toxic and complains of severe localized pain. The affected area often has a necrotic appearance from the underlying ischemia. Crepitus may be detected on examination. The diagnosis is made clinically. Once diagnosis is established the treatment is broad spectrum antibiotics (aminoglycoside, penicillin, and metronidazole), intravenous fluid resuscitation, and extensive surgical debridement. Numerous debridements are often required, the defect being closed at a later stage with tissue flaps or skin grafts $[94,99]$.

Neutropenic patients are at particular risk of developing a pseudomonas fasciitis known as ecthyma gangrenosum (Fig. 22.2) [6, 10, 31, 90]. The patient develops black necrotic ulcers on the buttocks and perineal region. These are initially small but without treatment will spread and coalesce. Unlike necrotizing fasciitis, the treatment is primarily medical with an antibiotic regime including aminoglycoside with an antipseudomonal cephalosporin or penicillin; granulocyte colony stimulating factor (GCSF) may help to revive the neutrophil count [4]. Close observation must be kept on the patient. If large necrotic areas develop then late surgical debridement may be required. Occasionally a diverting colostomy may be necessary.

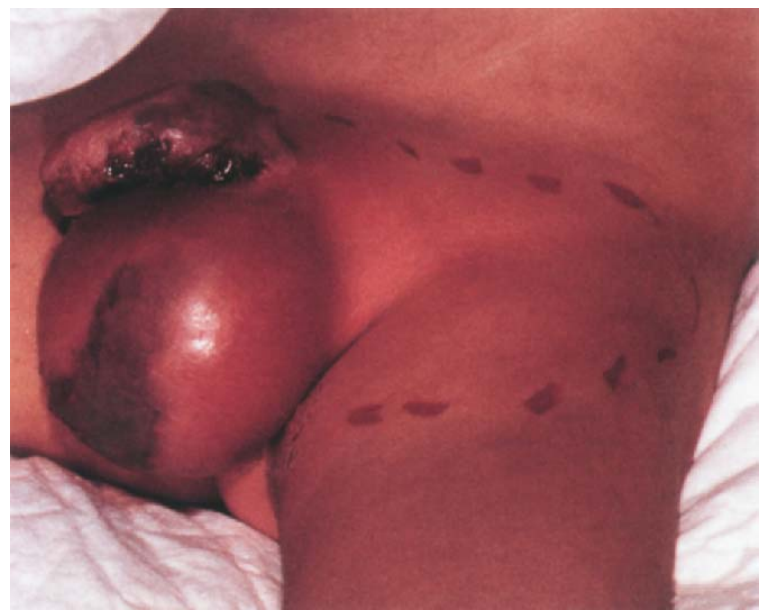

Fig. 22.2 Ecythema gangrenosum. This 3-year-old boy undergoing treatment of acute lymphoblastic leukemia became profoundly neutropenic 10 days after receiving chemotherapy. He developed a pyrexia and a hot erythematous penis and scrotum with areas of necrosis. Blood cultures and swabs of the area grew Pseudomonas aeruginosa. He was treated with antibiotics and G-CSF and recovered fully without the need for surgical intervention

\subsubsection{Compartment Syndrome}

Compartment syndrome is a rare problem in childhood and so is often overlooked till a late stage. It can develop in the presence of severe septicemia and shock, particularly after pseudomonas septicemia in the neutropenic patient. In our experience a septic child may complain of lower limb pain; however, as the child is so systematically unwell this can be overlooked. On examination the foot is plantar flexed with tight lower leg muscle compartments. There may be reduced skin sensation over the foot or parasthesia. The pathognomonic sign is extreme pain on the slightest attempt to actively or passively move the foot. Loss of pedal pulses is a late finding. The differential diagnosis is deep vein thrombosis, lower limb cellulitis, or an ischemic arterial problem. The diagnosis is a clinical one; checking compartment pressures and Doppler ultrasound studies can be misleading [78].

Despite the fact that these children are severely ill, surgical decompression under general anesthetic should be performed urgently. All four compartments should be opened right down over the ankle using a medial and lateral incision. The sooner this is done the better the chances of saving the muscles. Though muscle compartments expand markedly after release, use of a loose subdermal tacking suture allows apposition of the wound edge without increasing the compartment pressures. This reduces the need for skin grafting and thus gives a much better cosmetic result. Hemostasis with bipolar diathermy must be done scrupulously as bleeding is a major problem postoperatively. Numerous debridements of dead muscle may be required, although this should be left until demarcation has occurred. Delayed primary closure, tissue flaps, or skin graft may be used subsequently.

\subsection{Thoracic Complications}

Surgeons may be consulted by oncologists for advice and surgical intervention in children with thoracic complications. The most common request is for biopsying of suspicious lesions on a chest radiograph following treatment - the usual histological finding is of a benign lung scar; however, diffuse fibrosis secondary to chemoradiotherapy, recurrence of tumor, or fungal lesion are other important diagnoses. In addition, surgical consultation may be required to help with management of pleural effusions or severe hemoptysis. Other complications that may arise from thoracic structures involved with tumor, or from iatrogenic procedures, e.g., central lines, biopsy, or thoracoscopy or mediastinoscopy include the following. 


\subsubsection{Superior Vena Caval Syndrome}

The patient is unduly distressed following a procedure on the neck, e.g., after insertion of a central venous catheter or a biopsy. There is venous congestion of the face and neck with distended neck veins and petechial hemorrhage. Color Doppler ultrasound is useful to detect thrombosis in the great veins of the neck. Angiography via the catheter may demonstrate thrombus in the superior vena cava. Assessment at a low-radiation dose, 64-slice CT angiography has been helpful in diagnosing this condition [119]. Rarely, surgical intervention is indicated and most can be managed by supportive measures alone including heparin administration and removal of the central line from this location.

\subsubsection{Superior Mediastinal Syndrome}

This syndrome results in tracheal compression from trauma, biopsy of tumor (e.g., lymphoma of the mediastinum), or after thoracomediostinoscopy. Rapid intubation and treatment with antibiotics is indicated until the syndrome subsides. Rarely, a tracheostomy is indicated if this syndrome develops rapidly and unsuspected.

\subsubsection{Pneumomediastinum, Pneumopericardium, and Surgical Emphysema}

The "Michelin man" can be a complication after thoracoscopy from damage to the lung or the airway. This can be treated with antibiotics and a chest drain if a tension pneumothorax results. In rare instances this can occur as a complication of high-pressure ventilation therapy with dissection of air into their interstitial spaces.

\subsubsection{Cardiac Tamponade}

Cardiac tamponade may result after insertion of a central venous line and needs early recognition. Pericardiac drainage and replacement of a central line is needed.

\subsubsection{Pleurodesis}

Large malignant pleural effusions may cause respiratory embarrassment. If they do not settle with the treatment of the underlying disease they may require pleurodesis. Very little information has been pub- lished concerning children with malignant effusions; most pleurodesis has been undertaken for congenital lymphatic problems (chylothorax) or recurrent spontaneous pneumothorax.

Walker-Renard, et al. reviewed all the literature on pleurodesis of malignant lesions [112]. They found that response rates varied from $93 \%$ with talcum powder to $0 \%$ for etoposide. Doxycycline, tetracycline, and bleomycin all had success rates around $60-80 \%$. Bacillus Calmette-Guérin (BCG) vacine, quinacrine, and thioptepa were not assessed because of the lack of published data.

Talcum powder may be inserted into the pleural cavity using insufflation; this technique is best done under general anesthetic with thoracoscopy [121], although it can be inserted as a talcum slurry by tube thoracostomy under local anesthetic. Adult respiratory distress syndrome (ARDS), pulmonary edema, and granulomatous pneumonitis have all been described as complications developing postoperatively.

\subsubsection{Fungal Lung Lesions}

Opportunistic fungal infections are an important cause of morbidity and mortality in the immunosuppressed child. Fungal infections include those caused by Candida albicans, Aspergillus, zygomycetes Cryptococcus, and Mycobacterium avium [100]. The usual presentation of pulmonary fungal infection is fever, malaise, cough, or chest pain. Other problems which may develop include progressive respiratory distress or life-threatening hemoptysis.

Plain chest radiography may show a cavitating lesion, a mass, or pulmonary infiltrates, followed by computed tomography (CT) scan to more accurately identify the lesion (Fig. 22.3 a,b). Bronchoscopy with bronchioalveolar lavage may demonstrate fungal hyphae. Occasionally, either fine needle aspiration or an open biopsy of the lesion is necessary to achieve a definitive diagnosis. The most frequently identified organism is aspergillus. Treatment begins with appropriate antifungal agents, usually amphotericin B. Removal of the bulk of infected lung tissue improves the chances of eradicating the disease [100].

\subsubsection{Complications of Long Lines}

The development of tunneled silastic central venous catheters by Broviac and Hickman are among the most important milestones in the progress of pediatric oncology. However, as with all surgical procedures they are not without significant complications if they are not performed with care by an experienced operator. 

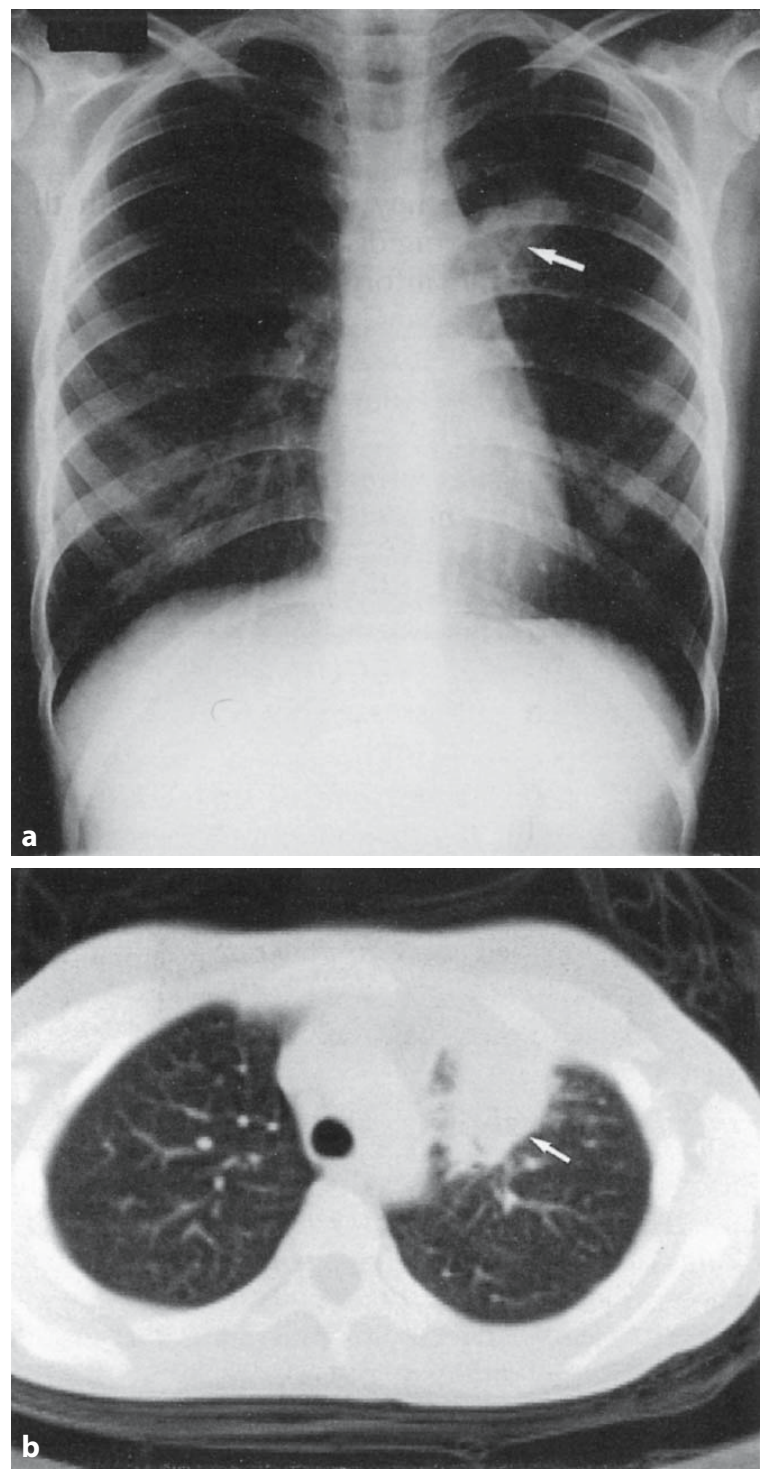

Fig. 22.3 a, b Aspergilloma. This patient, undergoing bone marrow transplantation for a relapsed leukemia, developed an invasive aspergilloma on her left upper lobe bronchus that was gradually eroding into her pulmonary vessels and causing her hemoptysis. Following a lobectomy and removal of the lesion she has made an uneventful recovery. (a) Chest x-ray of the patient. (b) CT scan of the same patient.

Central venous lines can be placed either percutaneously or at an open operation. Despite the more invasive procedure open placement is required for port insertion and may be actually safer as the vein is carefully identified and hence complications such as accidental puncture of the lung and tearing of the vein are minimized. Most children will require general anesthetic whichever technique is employed. See Chap. 27 [61].
Table 22.2 Complications of central venous catheters

\begin{tabular}{ll}
\hline & Complications \\
\hline Insertion & Hemothorax/hemomediastinum \\
& - Secondary tearing of the vein \\
& - Pneumothorax \\
& - Hematoma secondary to thrombocytopenia \\
& - Air embolus \\
& - Cardiac arrhythmias \\
Usage $\quad$ Infection & - Thrombosis of tip/vena cava thrombosis/ \\
& - atrial thrombus \\
& - Air embolus \\
& Line breakage causing bleeding, introduc- \\
& - Dislodgement \\
Removal & Air embolus \\
- & Catheter embolus to right side of heart \\
& or lungs \\
- & Dislodgement of septic thrombus
\end{tabular}

\subsubsection{Complications of Catheter Removal}

It is important to remember that most operative deaths associated with tunneled catheters occur when they are removed. The reasons for this may be that it is considered a simple procedure often attempted on the ward under local anesthetic or in the anesthetic room by the most junior surgeon. We have heard of three deaths directly attributable to removal of tunneled long lines - in two cases the line was accidentally divided and then embolized, and once a septic thrombus was dislodged; in all three instances a fatal pulmonary embolus resulted. For this reason all our cuffed line removals are done in the operating theater by the following technique. Unless the cuff is readily visible at the exit site a new incision is made proximal to the cuff and the fibrous tissue surrounding the line is dissected free. An incision is made in this fibrous casing in the long axis of the line to reduce the risk of severing the line. The distal part of the line can then be clipped and the line removed while a second person presses firmly over its point of insertion into the vein. The cuff can then be dissected out without risk of damaging the line or causing an air embolus. The incision and exit site are then sutured closed[30]. 


\subsection{Gastrointestinal Complications}

\subsubsection{Acute Abdominal Pain}

\subsubsection{Overview}

The development of the acute abdomen in a child being treated for neoplastic disease often provides the medical and surgical teams caring for that child with a diagnostic and therapeutic dilemma. The cause of the symptoms may be the same as those in a child of similar age without cancer or it may be related to the treatment of cancer. Even simple conditions may be confused by the immunodeficiency, the use of steroids, or cytotoxic drugs and other factors associated with the cancer and/or its treatment. This may lead to localized conditions becoming generalized and the clinical signs of sepsis and inflammation being masked. In addition, the management decisions are complicated by the fact that many of these children are seriously ill at presentation and wound healing may be impaired.

Assessment of the risks of all possible causes is necessary to determine whether a laparotomy is required or if intensive medical treatment is preferable. The present thinking is that both have their place even for the ill child [87], and hence the medical and surgical teams should work closely together in initial assessment and ongoing management.

Table 22.3 shows the likely causes of acute abdominal pain in children with cancer and a suggested structured approach to their treatment. Specific conditions are discussed in detail below.

Table 22.3 Causes of acute abdominal pain in children with cancer

\begin{tabular}{l}
\hline Diagnosis \\
Neutropenic enterocolitis \\
Pseudomembranous colitis (Clostridium difficile) \\
Cytomegalovirus/adenovirus enteritis \\
Acute graft-versus-host disease \\
Peptic ulceration (stress or steroids) \\
Pancreatitis \\
Hemorrhagic cystitis \\
Radiation enteritis \\
Obstruction \\
Perforation of bowel \\
Inflammatory cause \\
Intestinal lymphoma responding to treatment \\
Rupture of a Wilms' tumor \\
Hemorrhage into a tumor causing distension \\
Hepatic tumors \\
Sudden hepatomegaly stretching liver capsule \\
Hypercalcemia of malignancy
\end{tabular}

\subsubsection{The Role of Diagnostic Imaging}

Close cooperation with the radiology department is important for the diagnosis of the acute abdomen in children with cancer. While accurate diagnosis is essential, avoidance of invasive or time-consuming investigations is also important in these seriously ill children. Plain abdominal radiograph may show bowel dilatation, mucosal edema, a space-occupying lesion, free air (outlining the bowel wall), or pneumatosis intestinalis. An erect abdominal radiograph may show free air under the diaphragm though it may be normal in over $10 \%$ of bowel perforations; lateral decubitus abdominal radiographs (right side up) may be used in the severely ill patient.

Abdominal ultrasound is an excellent noninvasive method of assessing the bowel for intestinal wall thickness, free fluid, and collections of fluid within the abdomen. Normal colonic wall thickness is $\leq 2 \mathrm{~mm}$ [10]. It can also pick up appendicitis, cholecystitis, and pyelonephritis $[39,76]$. Ultrasound examination is relatively inexpensive, avoids ionizing radiation, and can be performed at the bedside. However, it must be remembered that ultrasound is operator-dependent and that excessive bowel gas, especially in the older child, can adversely affect the images; hence a negative scan does not necessarily rule out intra-abdominal pathology.

A CT scan is also noninvasive and requires both intravenous and oral contrast. Restless children will require sedation or general anesthetic for the study. In the immunocompromised patient, CT may demonstrate intra-abdominal abscesses, pseudomembranous colitis, typhlitis, graft-versus-host disease, radiation enteritis, and appendicitis $[23,70]$.

Contrast studies are beneficial in the relatively well child with chronic symptoms especially for diagnosis of strictures or radiation enteritis [68]. However, care must be taken in patients with colitis because of the risk of bowel perforation [67, 111]; for this reason we prefer to use water-soluble nonionic contrast medium.

\subsubsection{The Role of Endoscopy}

Surgeons are frequently called on to perform either upper or lower gastrointestinal endoscopy on patients with unexplained abdominal symptoms. The number of causes of abdominal pain or bleeding are numerous and, together with judicious use of diagnostic imaging, endoscopy and relevant biopsies may be essential for accurate diagnosis $[5,65,86,88]$.

Obtaining biopsies at endoscopy is not associated with significant sepsis even in severely immunosuppressed patients [49]. Upper gastrointestinal endoscopy can be used to sclerose esophageal varices or 
inject bleeding ulcers. Careful performance of colonoscopy in patients with viral colitis, typhlitis, and severe graft-versus-host disease is essential in order to avoid overdistension of the colon and reduce the risk of perforation.

\subsubsection{Assessment of Acute Abdominal Pain in the Child with Malignant Disease}

1. Full history with particular reference to the time of onset of pain with regard to other treatments, changes in the neutrophil count and changes in other physiological parameters, i.e., pulse, temperature, blood pressure, respiratory rate.

2. Full examination with special regard to the abdomen looking for focal or generalized tenderness and signs of peritonism. Avoid rectal examination in neutropenic patients if possible.

3. Blood tests to include full blood count, urea, electrolytes, amylase, liver function tests. Clotting studies may reveal disseminated intravascular coagulation. Arterial blood gas sample may show signs of an unexpected metabolic acidosis suggesting ischemia or sepsis. Remember that white cell count, C-reactive protein, and erythrocyte sedimentation rate may all be normal in the presence of immunosuppression.

4. Septic screen to include urine, stool, blood cultures, and sometimes lumbar puncture.

5. Diagnostic imaging - see above.

\subsubsection{Metabolic Causes of the Acute Abdomen}

This usually arises from two main metabolic disorders.

1. Hypercalcemia of malignancy. This can be caused by metastases, osteolytic bone tumors, or humoral factors secreted by endocrine tumors [51], e.g., parathyroid hormone. The symptoms are those of hypercalcemia (weakness, brachycardia, constipation, polyurea, peptic ulceration, and pancreatitis). Fluid resuscitation and pamidonate is of value in the management of acute cancer-related hypercalcemia in children.

2. Tumor lysis syndrome. This was often observed in the treatment of bulky lymphomas following chemotherapy but can occur with any large bulky tumor undergoing necrosis. A rare complication of germ cell tumors and calcium levels should be monitored in all children with solid ovarian masses [62]. The metabolic upset includes hyperuricemia, hyperkalemia, and hyperphosphatemia with hypocalcemia. The patient presents with severe abdominal pain from uric acid crystal crisis, lethargy, and anuria $[1,9,123]$. Calcification of the gastric mucosa has been reported in association with tumor lysis syndrome in a child with non-Hodgkin lymphoma [8].

The management of such a high-risk patient includes intravenous hydration with at least 2-3 liters/m2 over $24 \mathrm{~h}$ using quarter strength saline, 5\% dextrose, alkalization of the urine with sodium bicarbonate $100 \mathrm{meq} /$ liter titrating the urine to a ph of 7.0-7.5, drug therapy, allopurinol $300-500 \mathrm{mg} / \mathrm{m} 2$ for 3 days to prevent uric acid deposition, and careful monitoring of urine output, ph, urine electrolytes, and urea including calcium and phosphate. Occasionally, dialysis or hemofiltration may be necessary. Recombinant urate oxidase (rasburicase) may be used for prevention and treatment of tumor lysis syndrome in patients with hematological malignancies [114]. Rasburicase is a safe, highly and rapidly effective agent in the treatment and prevention of malignancy-associated acute hyperuricemia and could be considered the treatment of choice to prevent tumor lysis syndrome in children at high risk [79].

\subsubsection{Specific Causes of Abdominal Pain}

\subsubsection{Intestinal Obstruction}

Vomiting in a child being treated for malignant disease is very common; however, this must be differentiated from the emesis observed in numerous surgical conditions. Obstruction is due to mechanical blockage of the bowel and is common after operation for tumor $[84,98]$. Characteristically vomit is bile-stained (green) in mechanical obstruction and in adynamic paralytic ileus. Auscultation is an important denominator. Table 22.4 shows the causes of intestinal obstruction.

It must be noted that sometimes a child presents with obstruction due to abdominal lymphoma. There are two clinical scenarios to be aware of. The first is with localized ileo-cecal disease causing the lead point of an intussusception. In this case localized resection with primary anastomosis is the treatment of choice; biopsy of suspicious mesenteric lymph nodes may also help in staging. If there is diffuse disease then a biopsy alone with intense supportive management is sufficient as the disease will rapidly resolve once chemotherapy is started [14].

\subsubsection{Radiation Enteritis}

Clinical features. Acute systemic upset, with nausea, vomiting, diarrhea, abdominal pain, and gastrointestinal bleeding; commonly complicates radiotherapy to 
Table 22.4 Causes of obstruction in relation to the bowel wall

\begin{tabular}{ll}
$\begin{array}{l}\text { Position of } \\
\text { obstructing lesion }\end{array}$ & Diagnosis \\
\hline Outside the bowel & $\begin{array}{l}\text { Mass effect from large intra-abdominal } \\
\text { tumor (compression) }\end{array}$ \\
& Postoperative adhesions \\
In the bowel wall & $\begin{array}{l}\text { Primary or secondary tumor } \\
\text { within the bowel wall }\end{array}$ \\
& $\begin{array}{l}\text { Intussusception - after surgery for } \\
\text { Wilms' tumor [23], neuroblastoma } \\
\text { or other }\end{array}$ \\
& $\begin{array}{l}\text { Retroperitoneal procedures } \\
\text { Within the lumen }\end{array}$ \\
& $\begin{array}{l}\text { Tumor invasion of the lumen an anastomosis, } \\
\text { or from radiation enteritis, } \\
\text { or enterocolitis }\end{array}$ \\
& $\begin{array}{l}\text { Paralytic ileus } \\
\text { Opiate therapy }\end{array}$ \\
& $\begin{array}{l}\text { Vincristine therapy } \\
\text { [Adriamycin (doxorubicin) }] \\
\text { Anticholinergic effects of medication }\end{array}$ \\
& \\
&
\end{tabular}

the abdomen and pelvis. Although these acute symptoms usually resolve relatively quickly, about $5 \%$ of patients progress to chronic complications after the completion of radiotherapy $[35,68,117,120]$. Radiation damage to the bowel is dose dependent, although other factors such as previous operations, peritonitis, and concurrent chemotherapy (especially actinomycin-D) may all contribute to worsening the long-term problems [22]. More than one complication may occur and new lesions may develop at later stages; radiation enteritis should, therefore, be considered to be a progressive disease [35]. Complications related to the large bowel include proctocolitis, colorectal and anal strictures, rectal ulcers, spontaneous necrosis, and fistulae to bowel, bladder, or vagina. Small bowel complications include bleeding, adhesions, strictures, malabsorbtion, spontaneous necrosis, fistula, and poor anastomotic healing [117]. Bleeding and fistula or perforation seem to represent the two ends of the spectrum of radiation enteritis suggesting that bleeding represents just mucosal trauma whereas full-thick- ness bowel wall damage must be present for perforation and fistula formation [35]. Malabsorbtion of fat, vitamin B12, and calcium may also occur $[22,117]$.

Diagnosis. Diagnosis of the condition can be difficult. A history is important with regard to the time and dosage of radiation. An erect or supine abdominal radiograph may show features of obstruction or perforation. The most important investigations are contrast radiographs, and either small bowel studies or large bowel enemas. Radiological signs of small bowel disease include evidence of submucosal thickening, single or multiple stenoses, adhesions, and sinus or fistula formation [68]. Large bowel strictures usually appear smooth and concentric in outline [117].

Radiation enteritis causes severe villous blunting, distended lymphatics, and replacement of the normal columnar epithelium with cuboidal cells; a pattern consistent with the clinical findings of malabsorption. The submucosal changes include perivascular adventitial fibrosis. Microscopic changes can be found in macroscopically normal bowel $[22,117]$.

Treatment. Radiation enteritis is a progressive disease [120]. Many patients can be treated conservatively; $5-20 \%$ of patients may require surgical intervention $[46,35]$. The main indication for surgery is perforation. Patients with strictures are best treated conservatively, initially with bowel rest and decompression followed by low residue diets $[22,120]$. If obstruction or fistula makes operative intervention necessary then great care must be taken to handle the bowel gently and avoid resection wherever possible. A high incidence of anastomotic leaks follows bowel resection of irradiated bowel due to a compromised blood supply and poor wound healing. Extensive dissection of adhesions should be avoided and a side-to-side bypass operation considered in some cases. When a resection is inevitable, for instance after perforation or in response to chronic severe blood loss, then more generous resections should be made and the bowel temporarily exteriorized to avoid an anastomosis $[35,120]$.

Prophylaxis. Many techniques have been used to exclude bowel from the pelvis during radiation therapy for pelvic malignancy using omental slings, tissue expanders, and distension of the bladder or retroversion of the uterus. The use of pelvic vicryl mesh placed at the level of the sacral promontory seems to be the best option in children [69]. In a study of eight children undergoing pelvic irradiation for malignancy who had a pelvic mesh placed before radiotherapy, none suffered from radiation enteritis [69].

Adhesive obstruction. Previous laparotomy, intra-abdominal or pelvic irradiation, and intraperitoneal 
bleeding or sepsis may lead to adhesion formation. Hence, a child with an intra-abdominal tumor is at significant risk of the late complications of adhesion formation. Operation for adhesions caused by radiotherapy is unrewarding and dangerous; the bowel is often unhealthy, easily damaged, and the adhesions rapidly reform. Adhesions secondary to previous operations are best managed conservatively but failure of the obstruction to resolve after $48 \mathrm{~h}$ and signs of ischemia are absolute indications for laparotomy.

\subsubsection{Treatment of Obstruction in the Terminally III Child}

Obstruction may occur in the advanced stages of childhood malignancy and although it may be a preterminal event, its management is important for symptom control. Traditional treatment includes stopping oral intake, insertion of a nasogastric tube, decompression, intravenous fluids, and correction of electrolyte abnormalities. Medical management includes anticholinergics, antiemetics, and analgesics. The role of steroids to reduce the degree of perineoplastic inflammation is controversial. Octreotide is a somatostatin analog that stimulates water and electrolyte absorption and inhibits water secretion by the small intestine. It may be useful in the treatment of obstruction and enteric fistulae [113]. Operative intervention with colostomy or bypass procedure may be justified. However, it may be more appropriate to manage these patients with intravenous opiates alone.

\subsubsection{Neutropenic Enterocolitis}

Though this condition may affect any part of the bowel, the most common area to be affected is the distal ileum and cecum and hence the term "typhlitis" is often used. It describes the clinicopathological syndrome of necrotizing inflammation of the cecum occurring in neutropenic patients. Though many cases of appendicitis complicating neutropenia had been described [27]. (usually with fatal results), it was not until 1961 that Amromin first recognized that neutropenic enterocolitis of the cecum was a distinct entity $[2,63]$.

Incidence. Exact incidence rates are difficult to collect because of the paucity of large studies and the difficulties of defining the relevant population. Several series have suggested an overall incidence of approximately $5 \%$ in patients with acute leukemia $[29,72,91]$.

Etiology. The condition only develops in the presence of profound neutropenia. This may be disease induced [hematological malignancy, aplastic anemia and immunodeficient diseases such as human immunodeficiency virus (HIV)-induced acquired immunodeficiency syndrome (AIDS)] or secondary to drug treatment (chemotherapy for malignancy and bone marrow transplantation). The condition appears to be more common in acute myelogenous leukemia than in other forms $[72,87]$.

No definite cause has ever been identified but several hypotheses exist. Damage to the bowel mucosa allows invasion by colonic flora. Septicemia can then develop unchecked by the depleted immune system. Later, shock may increase the ischemia and thus perpetuate the vicious cycle. The initial mucosal insult is probably multifactorial including a direct effect of cytotoxic drugs on the mucosa, profound neutropenia, mucosal hemorrhage due to associated thrombocytopenia, stasis, and by changes in the bacterial flora secondary to prophylactic antibiotics $[3,87,111,116]$. Why the cecum is most commonly affected is not clear though stasis and a relatively poor blood supply are possible explanations.

The theory that leukemic infiltrates of the bowel wall become necrotic in response to chemotherapeutic regimens causing damage to the mucosal wall and local hemorrhage appears plausible but there is little evidence, on microscopic examination, to support it.

Clinical features. Typically a patient undergoing induction chemotherapy is rendered neutropenic and develops problems between day 4 and 14. Symptoms and signs include diarrhea, vomiting, gastrointestinal bleeding, abdominal distension and sepsis. Examination usually reveals an ill patient with pyrexia, tachycardia, hypotension, and peritoneal irritation which may be diffuse or limited to the right iliac fossa $[29,36$, $67,72,80,87,91]$.

Pathology. Grossly edematous cecum, mucosal ulceration, congested mesentery, and hemorrhagic mucosa progressing to full thickness necrosis of the bowel wall are seen at laparotomy. Three characteristic anatomical distributions are seen. First, the necrosis is sharply localized to the cecum with relative preservation of the ileum; second, the cecum is involved in extensive disease with other portions of the colon and small intestine; and third the cecum may contain ulcers which also occur sporadically throughout the intestine [111].

The tissues are edematous and blood vessels are dilated and engorged. Tissue structures appear necrotic and frequently masses of organisms are seen within the lesions. Leukemic infiltration is rarely seen but when present is readily identifiable. The usual microscopic pattern is one of hemorrhagic necrosis involving the mucosa and submucosa with a striking lack of acute inflammatory reaction. Occasionally, an exudate 
resembling a pseudomembrane and consisting of fibrin and cell debris may be found overlying the most severely ulcerated mucosal surfaces. In later stages the process may progress to full thickness involvement of the bowel wall and perforation.

Differential diagnosis. Causes of acute abdominal pain in these patients include acute appendicitis, pseudomembranous colitis, intussusception, pancreatitis, and pelvic abscess [29]. However, studies have shown that the most likely cause of diffuse or localized right iliac fossa abdominal pain in neutropenic patients is typhlitis $[70,72,87,111]$.

The most common organism isolated in septic patients with typhlitis is Pseudomonas aeruginosa [67, 111] though other Gram-negative organisms such as Escherichia coli and Klebsiella are also commonly found $[29,87,91,92,116]$. Gram-positive bacteria and fungi are occasionally found $[29,36,111]$. It is important to send multiple stool samples for analysis of C. difficile and its toxins to rule out pseudomembranous colitis.

Investigations. Blood tests are of little help, except to confirm neutropenia (neutrophils $<0.5$ ). Other markers of infection and inflammation can be misleading due to the effects of steroids, cytotoxic drugs, and general bone marrow suppression.

Diagnostic imaging studies are essential. Plain radiographs of the abdomen may show a paucity of bowel gas in the right iliac fossa progressing to a right-sided, ill-defined soft tissue mass due to a fluid-filled atonic cecum [111]. Other signs include small bowel ileus, ascites, and occasionally cecal pneumatosis which may not appear until the terminal stages of the disease process. Contrast enema findings include thickened mucosal folds, "thumb-printing" due to edema of the mucosa and cecal contraction [67]. Filling of the appendix rules out acute appendicitis. Contrast enemas may precipitate perforation of the cecum in the debilitated child $[70,111]$.

The investigation of choice is abdominal ultrasound $[76,92]$. Sonographic features of typhlitis include the so-called target sign of a rounded mass with a highly echogenic center and a wide hypoechoic periphery. Remember that this sign is also seen in malignant tumors of the bowel, intussusception, and bowel infarction $[67,76,92] .30,35,61$ Appendiceal thickening may indicate an increased risk of serious complications from this disease process [64].

If the ultrasound is not diagnostic or there is a suspicion of a more sinister cause then CT scan should be used. It can detect transmural inflammation, cecal wall thickening, soft tissue mass, and pneumatosis [70, 92].

Having ruled out intussusception, the finding of a soft tissue inflammatory mass in the right iliac fossa by ultrasound or CT in a neutropenic patient with pain and sepsis should be considered diagnostic of typhlitis $[39,70,92]$.

Management. Management of these patients remains controversial, and both surgical $[29,72,91,110,116]$ and conservative medical management have been advocated [36, 87]. Recently, large series have shown that aggressive medical treatment with bowel rest, fluid resuscitation, and broad spectrum antibiotics together with selective surgical intervention are associated with good outcomes [87, 92]. Children are treated with intravenous fluids and triple antibiotics (benzylpenicillin, netilmicin, and metronidazole) and closely observed with frequent reassessment by the surgical team, for signs of deterioration. Granulocyte colony stimulating factor (GCSF) has been employed to hasten the return of the neutrophils but thus far its benefits in typhlitis have not been confirmed.

The main indication for surgical intervention is perforation; the other indications for operation include persistent gastrointestinal bleeding despite correction of thrombocytopenia and coagulation defects or clinical deterioration despite maximal supportive therapy. The child will benefit from removal of the source of abdominal sepsis by resection of necrotic bowel and peritoneal lavage [28]. It is important to rule out surgically treatable causes such as intussusception or acute appendicitis. Prognosis is better if the patient is in remission at the time of the operation [29].

Using a combination of aggressive medical and selective surgical management the two largest recent studies have shown a mortality of approximately $8 \%$ $[87,92]$.

\subsubsection{Pancreatitis}

Pancreatitis may rarely develop in some children with cancer following treatment with L-asparaginase, azathioprine, thiazide diuretics, and corticosteroids [60]. In addition it can complicate raised intracranial pressure [25]. or hypercalcemia [60, 104]. After L-asparaginase up to $6.5 \%$ of patients will develop pancreatitis [74]. L-asparaginase-induced severe narcotizing pancreatitis has been successfully treated with percutaneous drainage used to flush the infected necrotic parts [103].

Clinical features include severe abdominal pain, vomiting, and shock. Diagnosis is confirmed by a raised serum amylase or lipase level [93]. Full blood count, urea and electrolytes, serum calcium, liver function tests, clotting screen, and an arterial blood gas (ApO2) should be obtained. Chest radiograph can show signs of adult respiratory distress syndrome (ARDS). The abdomen should be assessed by either 
ultrasound examination or CT scan [76, 93] evaluated for edema, fluid collection, hemorrhage, necrosis, and other complications of pancreatitis.

Treatment is essentially medical, aimed at correction of the shock-like state of the patient with aggressive fluid resuscitation, nasogastric tube insertion, and drainage bowel rest. Intensive care is required if complications such as severe hypocalcemia, disseminated intravascular coagulation or respiratory distress associated with hypoxia develop [93]. Antibiotics may be required particularly in patients who are immunocompromised. Complications of pancreatitis include pancreatic abscess, which often requires urgent debridement and drainage. Pseudocysts may also occur but often will resolve, although in some instances may require drainage either percutaneously or by operative treatment. Octreotide has been used successfully in a child with L-asparaginase induced hemorrhagic pancreatitis [38].

\subsubsection{Cholecystitis}

Though rare, cholecystitis should always be considered in the differential diagnosis of the acute abdomen. In particular acute acalculous cholecystitis is associated with stress, sepsis, and co-existing problems such as leukemia [105]. The usual presentation is with rightupper quadrant pain, pyrexia, and vomiting; jaundice and a palpable mass are sometimes found. Diagnosis is confirmed by ultrasonograph demonstration of gallbladder distension, thickening of the gall bladder wall, pericholecystic fluid collection, and lumen sludge. Patients with cholecystitis usually respond to conservative management with intravenous fluids and antibiotics [105]. Unresponsive cases may require percutaneous drainage or cholecystectomy, either laparoscopically or by open surgery.

\subsubsection{Ruptured Tumor}

Occasionally the cause of the acute abdominal pain is the result of a ruptured tumor. This has been described in patients with Wilms tumor, hepatoma, neuroblastoma, and B-cell lymphoma. This is often the result of trivial trauma in a child with an unsuspected neoplasm, but can occur spontaneously. Tumor rupture results in a more advanced stage of the disease process and requires more aggressive treatment. Godzinski found that survival after acute nephrectomy for ruptured Wilms' tumor was good but that this was achieved at the expense of long-term morbidity from using doxurubicin (adriamycin) and radiotherapy [42] (Fig. 22.4). An arteriovenous fistula and hemorrhage has been reported as a complication

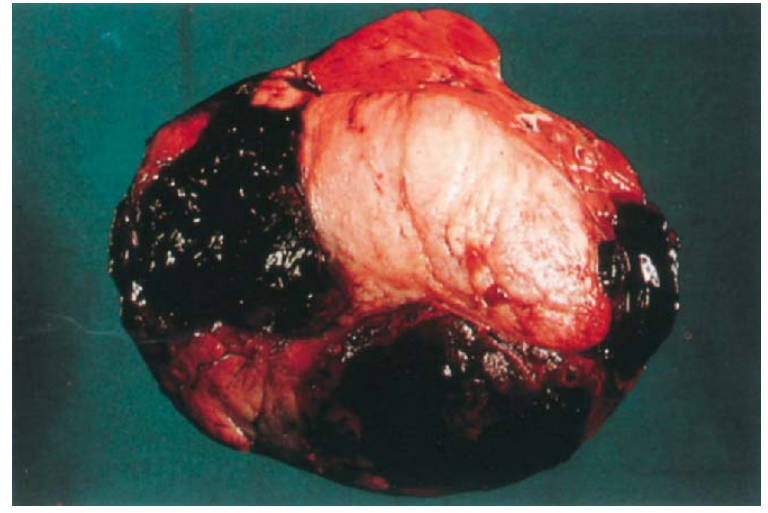

Fig. 22.4 Subcapsular hematoma in a Wilms' tumor. This was about to rupture and had to be removed as an emergency procedure.

following renal biopsy of a suspected bilateral Wilms' tumor [20].

\subsubsection{Gastrointestinal Bleeding}

Surgeons are occasionally asked to evaluate children on the oncology unit with gastrointestinal bleeding. This can range from small specks of altered blood to frank life-threatening hemorrhage. A list of conditions associated with gastrointestinal hemorrhage is presented in Table 22.5.

Gastric Antral Vascular Ectasia. This is a condition that is being increasingly reported in BMT patients. It was first described by Rider 1 back in 1953 but recently has been noted in patients undergoing transplantation $[12,42]$. It causes acute and chronic blood loss, at endoscopy the appearance is of red patches within the stomach. Histology shows dilated submucosal capillaries, fibrin thrombi, and fibromuscular hyperplasia. There should be no evidence of GVHD, infection, or ulceration. Ohashi reported five cases all of whom had received conditioning therapy with busulfan and all had a history of microangiopathy.3 Treatment was supportive but did not seem to respond to omeprazole in three of the five patients. Selective angiography had suggested high venous pressures so they were tried on the cardio-selective beta blocker Metoprolol with good results.

\subsubsection{The Role of Diagnostic Imaging in Acute Gastrointestinal Bleeding}

Plain radiographs are rarely useful but may show toxic dilatation of the colon in acute colitis. Contrast studies 
Table 22.5 Causes of gastrointestinal bleeding

\begin{tabular}{|c|c|}
\hline Site & Cause \\
\hline Whole bowel & $\begin{array}{l}\text { Tumor infiltration of bowel } \\
\text { Mucosal ulceration from chemoradiotherapy } \\
\text { Lymphoma } \\
\text { Acute graft-versus-host disease } \\
\text { Thrombocytopenia } \\
\text { Depletion of clotting factors }\end{array}$ \\
\hline Liver & $\begin{array}{l}\text { Porto-systemic hypertension and varices } \\
\text { Impaired production of clotting factors } \\
\text { Veno-occlusive disease }\end{array}$ \\
\hline Esophagus & $\begin{array}{l}\text { Esophageal varices } \\
\text { Viral/fungal esophagitis } \\
\text { Gastroesophageal reflux } \\
\text { Mallory-Weiss tears }\end{array}$ \\
\hline $\begin{array}{l}\text { Stomach and } \\
\text { duodenum }\end{array}$ & $\begin{array}{l}\text { Peptic ulceration (stress or steroid induced) } \\
\text { Gastric erosions } \\
\text { Gastric antral vascular ectasia }\end{array}$ \\
\hline Small bowel & Enteritis (see below) \\
\hline Large bowel & $\begin{array}{l}\text { Neutropenic enterocolitis } \\
\text { Radiation enteritis } \\
\text { Infective colitis (cytomegalovirus, } \\
\text { herpes simplex virus, adenovirus, } \\
\text { cryptosporidia, Giardia, Candida) } \\
\text { Clostridium difficile infection }\end{array}$ \\
\hline $\begin{array}{l}\text { Non-oncolo- } \\
\text { gical causes }\end{array}$ & $\begin{array}{l}\text { Ulcerative colitis } \\
\text { Meckel's diverticulum } \\
\text { Anal fissure } \\
\text { Hemorrhoids } \\
\text { Intestinal duplication } \\
\text { Hemangioma }\end{array}$ \\
\hline
\end{tabular}

should be avoided as they yield little useful information and prevent more useful investigations such as angiography.

Angiography and red cell scans are difficult to set up and time consuming and thus should be held in reserve until upper or lower gastrointestinal endoscopy fail to provide a diagnosis. Angiography has the advantage of accurately detecting the site of the bleeding if the rate exceeds $1.0 \mathrm{cc} / \mathrm{min}$ and can be used to embolize a bleeding point. The disadvantage of angiography is that it is an invasive procedure. Radiolabeled red cell scan, on the other hand, can be used in cases with a slower bleeding rate $(0.5 \mathrm{cc} / \mathrm{min})$ but provides less precise anatomical location of the bleeding point.

\subsubsection{The Role of Endoscopy in Acute Gastrointestinal Bleeding}

Upper and lower gastrointestinal endoscopy are the most rewarding procedures in detecting the site of bleeding. In a bleeding peptic ulcer endoscopic injection of the ulcer bed with epinephrine and heater probe coagulation may stop the bleeding. In rare instances of liver damage associated with portal hypertension, esophageal varices may be the cause of bleeding and can be injected with sclerosing agents or banded.

\subsubsection{Algorithm for Management of Gastrointestinal Bleeding}

A recommended algorithm for the management of patients with gastrointestinal bleeding is shown in Fig. 22.5.

\subsubsection{Esophagitis in the Immunosuppressed Patient}

The esophagus is a frequent site for infection in the immunosuppressed patient. Patients present with dysphagia, retrosternal chest pain, fever, and upper intestinal bleeding. The patient's symptoms, oropharyngeal cultures and esophageal contrast radiography are not predictive of the cause - therefore, accurate diagnosis depends on endoscopy, mucosal biopsy, and brushings of abnormal-appearing areas and cultures [65].

Endoscopic findings range from discreet vesicles in herpes simplex virus (HSV) esophagitis to erosions and a spectrum of findings from esophagitis to gross ulceration which may complicate any infection and is compounded by gastroesophageal reflux. The most common infecting organism was HSV followed by cytomegalovirus (CMV). Fungal infection also occurs and is usually due to Candida albican [65]. Treatment is supportive with adequate analgesia and appropriate antiviral or antifungal therapy.

\subsubsection{Infectious Colitis}

Immunocompromised patients are at high risk for development of opportunistic infections. Affecting agents include Candida albican, pneumocystitis carnii, C. difficile, cryptosporidia, giardia, CMV, HSV, rotavirus, astrovirus, and adenovirus. Cytomegalovirus infection is particularly associated with colitis and bowel perforation [43]. Investigation of diarrhea includes sending stool culture for anaerobic organisms, C. difficile toxin, and microscopy and culture looking for protozoa, fungi, or viral infestation. Viral infec- 


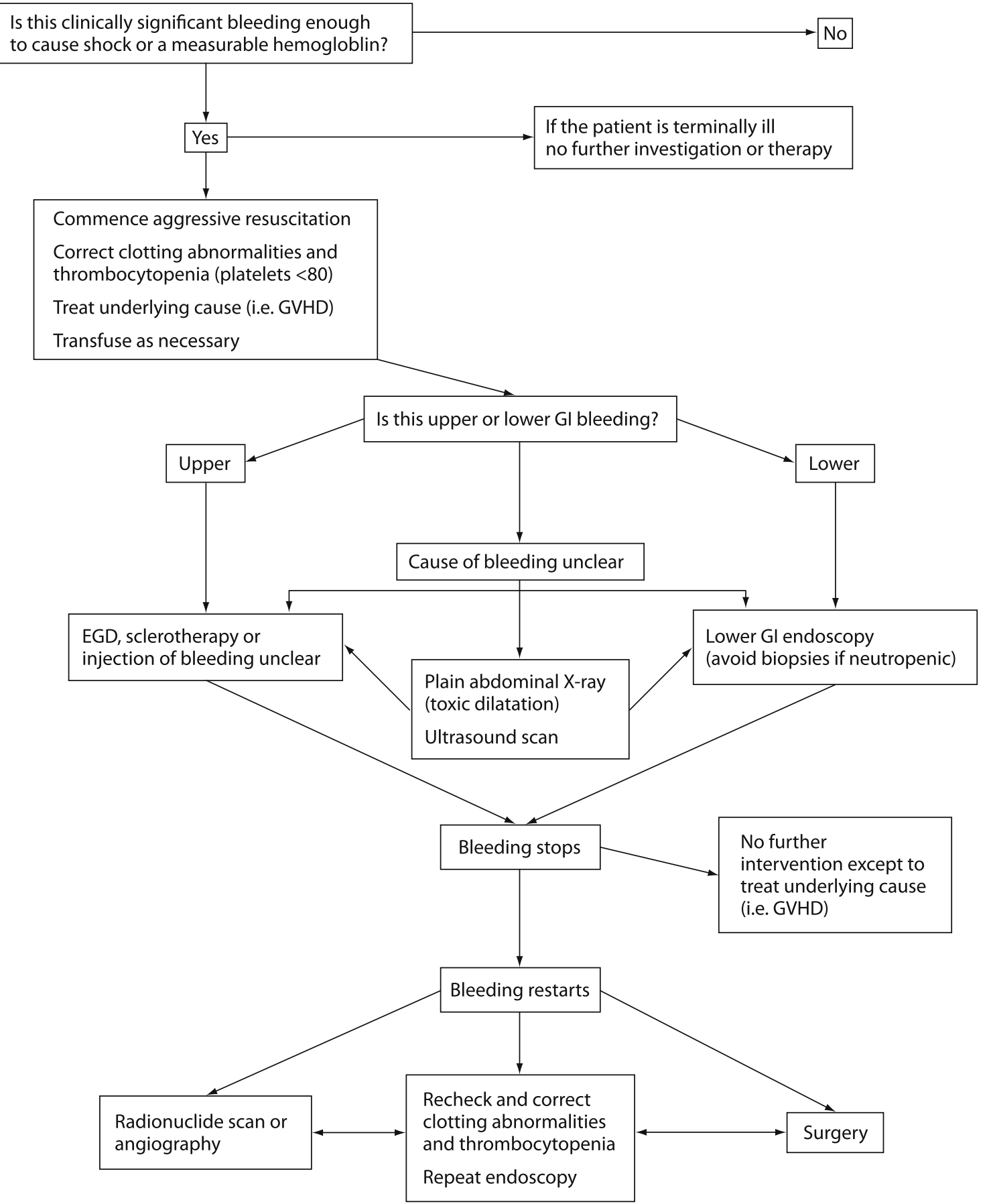

Fig. 22.5 Algorithm for management of gastrointestinal bleeding. GVHD, Graft-versus-host disease; GI, Gastrointestinal; EGD, Esophagogastro-duodenoscopy.

tion is of particular importance in the bone marrow transplant patients as clinically it is difficult to differentiate infection from acute graft-versus-host disease. The consequences of increasing the level of immunosuppression to treat graft-versus-host disease, when the patient is actually suffering from viral colitis, can result in a fatality. Sigmoidoscopy or colonoscopy are useful in making the diagnosis by providing biopsies from affected areas of colon for histology [52, 122]. Histological examination of biopsies may show viral inclusion bodies or fungal colonies. Appropriate 


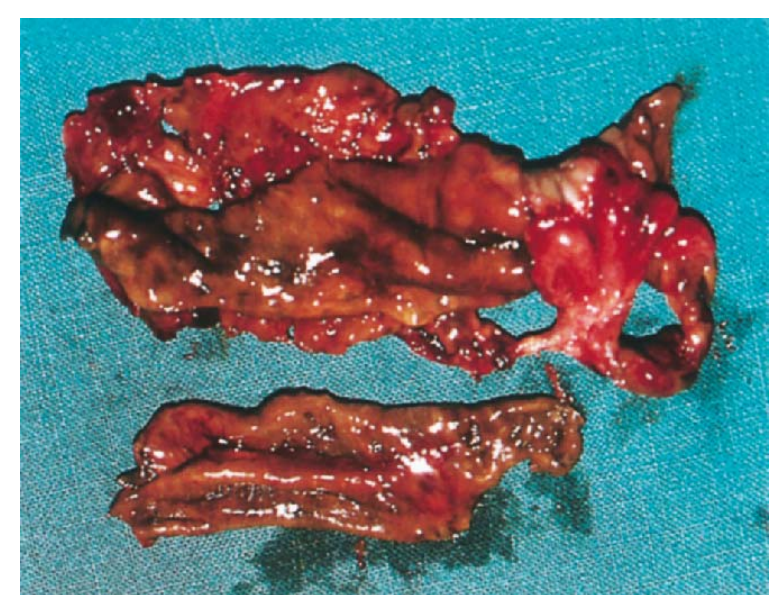

Fig. 22.6 Pseudomembranous colitis.

treatment for proven viral infection is with aciclovir or ganciclovir.

Clostridium-difficile-associated diarrhea is now a common problem in hospitals. Changes in the normal bacterial flora of the colon as a result of antibiotic therapy (especially clindamycin and in infants ampicillin) allows overgrowth of $\mathrm{C}$. difficile with subsequent release of toxins that cause mucosal damage and inflammation [50]. Clinical presentation includes mild to moderate diarrhea, antibiotic-associated colitis with or without pseudomembrane formation, and fulminant colitis (Fig. 22.6). Associated symptoms include abdominal cramps and bloody diarrhea. In instances of fulminating colitis the patient presents with an acute abdomen, fever, tachycardia, and lethargy. Toxic dilatation may develop. Diagnosis depends on demonstration of C. difficile toxins in the stool; sigmoidoscopy or proctoscopy and biopsies may be beneficial as most disease is confined to the rectum or sigmoid. However, in $10 \%$ of cases the colitis is limited to the proximal colon. Unfortunately, colonoscopy in these latter cases, in patients with fulminant colitis, may be complicated by perforation.

The treatment of C. difficile associated colitis is cessation of prior antibiotics, and treatment with vancomycin or flagyl preparations is mandatory. Barrier nursing of infected patients is recommended. Though severe colitis can usually be controlled within $48-72 \mathrm{~h}$ with antibiotics and appropriate supportive treatment, in some cases this fails and perforation occurs. Emergency celiotomy is mandatory for instances of proven perforation or severe refractory cases unresponsive to nonoperative management $[13,50]$ colectomy, ileostomy and construction of a Hartman pouch are often required.

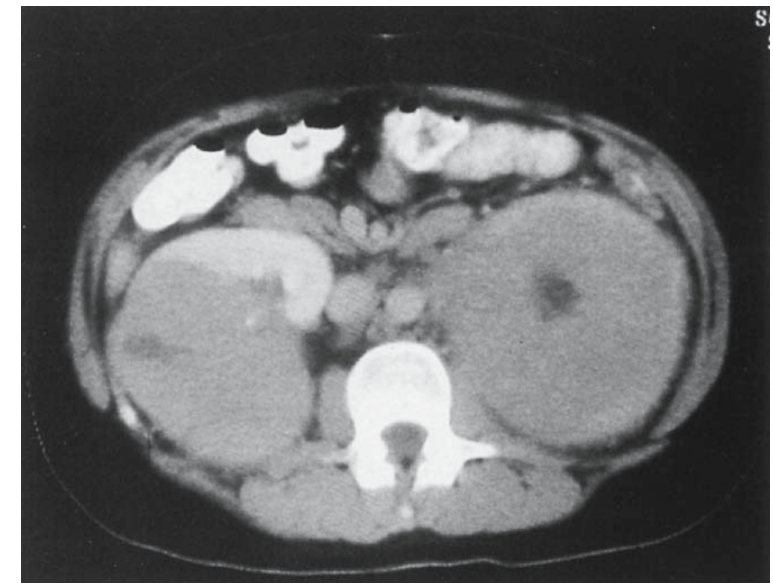

Fig. 22.7 Bilateral infiltration of the kidney in a patient with recurrent T cell lymphoma: CT scan showing both kidneys involved. This patient had to be treated by dialysis for renal failure.

\subsubsection{Perianal Lesions}

Perianal lesions include localized infections, abscesses, and other causes of inflammation such as graft-versushost disease and radiation proctitis.

Measures to avoid perianal infections include the following points:

1. Avoid rectal examination and the use of suppositories and enemas.

2. Avoid constipation using laxatives/stool softeners.

3. Avoid diarrhea. Clean perianal skin carefully with water (Sitz baths) and soft cloth. Barrier cream may reduce any skin reaction.

Symptomatic perianal infections are a relatively common occurrence in the neutropenic child, complicating $6 \%$ of hospitalized leukemic patients [44]. In the case of the profoundly neutropenic patient, no abscess will develop because of the lack of neutrophils to produce pus. The usual findings are of a mixed culture of colonic organisms [4, 41]. Pseudomonas aeruginosa is particularly pathogenic in this region and may quickly progress to necrotizing fasciitis of the anorectal region [4].

Unlike the patient with an intact immune system where surgical incision and drainage of the abscess forms the basis of treatment, the immunocompromised patient should be treated primarily with broad spectrum antibiotics that cover anaerobic and Gram-negative organisms. The regime used includes intravenous benzylpenicillin, netilmicin, and metronidazole. Granulocyte colony stimulating factor may hasten the return of an immunological response though its role is yet to be proven. Constipation should be treated with stool softeners and laxatives. Pain relief may be required. These patients should be observed closely to make sure 
that no abscess develops when the neutrophil count rises and that the cellulitis does not spread resulting in a necrotizing fasciitis $[4,41,75]$. Indications for surgical intervention are obvious fluctuation, a significant amount of necrotic tissue, or progression to a necrotizing infection $[44,75]$. There appears to be no increased morbidity or mortality in those requiring operation [44, 75]. The usual procedure is drainage of the abscess.

\subsection{Genitourinary Tract Complications}

Renal failure may be a complication seen after many years following treatment with cytotoxic agents and radiotherapy. Patients with neuroblastoma and Wilms' tumor are especially susceptible. Another complication seen in patients receiving therapy for bulky tumor is that of uric acid nephropathy discussed under metabolic causes of the acute abdomen (see "tumor lysis syndrome," above).

\subsubsection{Hemorrhagic Cystitis}

Hemorrhagic cystitis is a complication resulting from cancer therapy. Several causes have been identified, including alkylating agents, infections, and pelvic irradiation.

The oxazaphosphorine alkylating agents, cyclophosphamide and ifosfamide, are the most important causes. Cyclophosphamide was first introduced as an antineoplastic agent in 1957. Within 2 years Coggins, et al. had reported cases of significant hemorrhagic cystitis (Fig. 22.8) [19]. Acrolein, a liver metabolite of cyclophosphamide produced by microsomal enzymatic hydroxylation, has been identified as the cause of the cystitis. The exact mechanism of action is unknown but contact of acrolein with the urothelium causes sloughing of epithelium, development of inflammatory infiltrates, regeneration of a thinner epithelium, and formation of new blood vessels.

Numerous infectious causes are known. Viral pathogens include BK virus, polyoma virus, adenovirus, and cytomegalovirus. They are thought to be most significant in bone marrow transplant patients who are immunosuppressed and already sensitized by cyclophosphamide. These patients seem to develop a late hemorrhagic cystitis weeks or months after transplantation - there may be a link with graft-versus-host disease. Bacterial causes include E. coli, Klebsiella and Proteus, and fungal causes such as Candida albicans, Aspergillus fumigatus and Cryptococcus neoformans are also implicated in immunosuppressed patients [97].

\subsubsection{Incidence}

The incidence of hemorrhagic cystitis ranges from 2\% to $40 \%$ in adults; in children this complication seems to be less frequent at around 5-10\% [55]. The complication appears to be more frequent during the summer, suggesting that there may be a link with dehydration.

\subsubsection{Clinical Features}

The urological side-effects vary from transient irritative voiding symptoms, including urinary frequency, dysuria, urgency, suprapubic discomfort and stangury with microscopic hematuria, to life-threatening hemorrhagic cystitis [57, 95]. Late complications include bladder fibrosis, necrosis, contracture, and vesicoureteric reflux. The onset of symptoms is variable and may occur during the course of therapy or for several months later [57].

Though the severity of hemorrhagic cystitis does not appear to be dose-related, pediatric patients seem to develop cystitis at lower dosage and shorter duration compared with adults - this may be a consequence of the parenteral route of administration used in most children. There is no correlation with age or sex $[55,95]$. However, it is a common complication of allogenic blood and marrow transplantation. In a recent paper they concluded it is more prevalent in matched unrelated donors and unrelated cord blood transplantation than matched related donors [28].

\subsubsection{Diagnosis}

The diagnosis is often made clinically. Urine culture must be obtained to rule out infection. Excretory urograms may show anatomical defects and ultrasound can be diagnostic of hemorrhagic cystitis [53]. Urine cytology is frequently used in adults but has not been useful in children. Urine should be examined by electron microscopy for viral infection. Definitive diagnosis requires cystoscopy and biopsy, and can be useful in ruling out other causes.

\subsubsection{Prevention}

Adequate hydration, diuresis, and frequent bladder voiding all reduce the concentration and the time for which the toxic urine is in contact with the bladder $[57,95]$. Care must be taken not to cause overhydration as cyclophosphamide is known to cause damage to renal tubules and inappropriate water retention. 


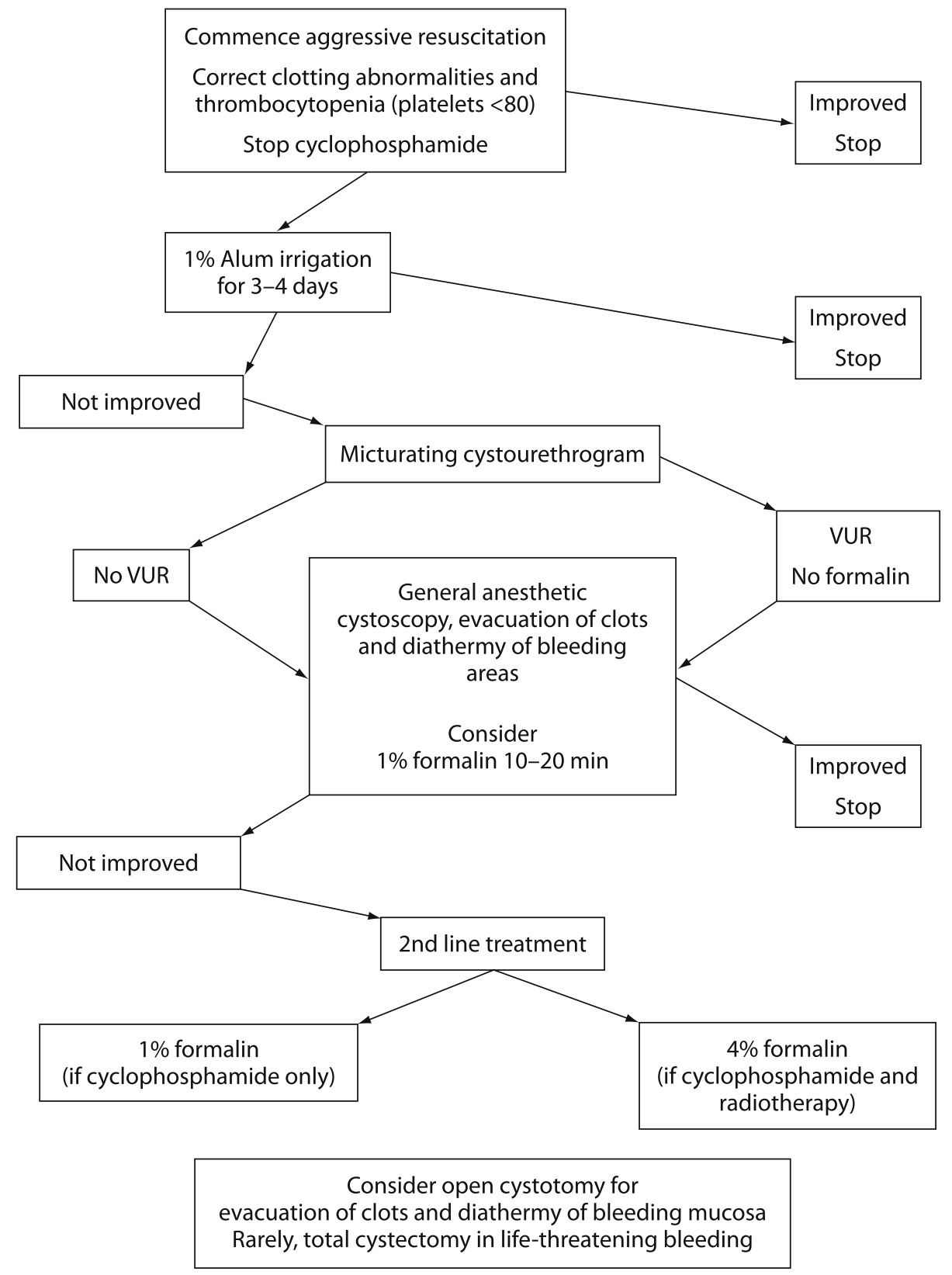

Fig. 22.8 Algorithm for treatment of cyclophosphamide-induced hemorrhagic cystitis as used at the Bristol Royal Hospital for Sick Children. VUR, vesicoureteric reflux.
N-Acetyl cysteine and more recently Mesna (2mercaptoethane sulfate) have been shown to reduce the incidence of cyclophosphamide-related cystitis $[57,97]$ by binding and inactivating the toxic acrolein (Table 22.6).

\subsubsection{Treatment}

Many different therapies have been suggested over the last 40 years, few of which have been rigorously tested by randomized controlled trials. Several of the
Table 22.6 Mesna prophylaxis given for cyclophosphamide therapy at the Bristol Royal Hospital for Sick Children

$20 \mathrm{mg} / \mathrm{kg}$ of intravenous Mesna in $0.9 \%$ saline given together with the cyclophosphamide over $1 \mathrm{~h}$

$76 \mathrm{mg} / \mathrm{kg}$ of intravenous Mesna in maintenance fluids ( $5 \%$ dextrose and $0.225 \%$ saline) over the next $23 \mathrm{~h}$

Each urine is checked by dipstix for microscopic hematuria If hematuria is found then a further $24 \mathrm{~h}$ of Mesna is given Any further doses of cyclophosphamide receive the same regime 
management possibilities have only been described in adults (Table 22.7). Fresh frozen plasma, platelets, and blood transfusion should be given as required.

Levine and Richie [57] suggested an algorithm for treatment based on the severity of the disease. Mild acute disease simply requires cessation of cyclophosphamide with good hydration and oral analgesia [55]. More severe disease justifies a more aggressive approach with cystoscopic evacuation of all mucosal clots followed by continuous bladder irrigation with $1-2 \%$ alum aluminum potassium sulfate for $2-3$ days through a large-bore catheter; alternatively intravesical instillation of prostaglandin F2 followed by cystoscopy, diathermy of any bleeding sites, and instillation of $2.5-4 \%$ formalin. In very small children in whom only a very small cystoscope can be passed our experience has been that open cystotomy, clot evacuation, and diathermy of bleeding points can provide excellent control of symptoms and should be considered at an early stage. In unresponsive cases with massive hemorrhage, total cystectomy may be a life-saving procedure.

Though formalin is a well-described treatment, it must be used with extreme caution because of complications of fibrosis, stricture, and renal damage. Before it is used a micturating cystourethrogram must be

Table 22.7 Various treatments described for cyclophosphamide induced hemorrhagic

\begin{tabular}{ll} 
Treatment & Ref. \\
\hline Cessation of cyclophosphamide & {$[57]$} \\
Hyperhydration & {$[57]$} \\
Frequent or continuous bladder emptying & \\
Continuous irrigation & {$[107]$} \\
$\begin{array}{l}\text { Correction of clotting } \\
\text { and platelet abnormalities }\end{array}$ & {$[21,37,54$,} \\
$\begin{array}{l}\text { Intravesical therapy with formalin, } \\
\text { alum or prostaglandin F2 }\end{array}$ & $56,73,82,89]$ \\
$\begin{array}{l}\text { Cystoscopy with evacuation of clot } \\
\text { and diathermy or laser } \\
\text { of hemorrhagic areas }\end{array}$ & {$[45]$} \\
$\begin{array}{l}\text { Open cystotomy, clot evacuation, } \\
\text { and diathermy } \\
\text { Systemic estrogen } \\
\text { Antiviral therapy if urine cultures } \\
\text { are positive } \\
\begin{array}{l}\text { Cystectomy and neobladder substitution } \\
\hline\end{array}\end{array}$ \\
\hline
\end{tabular}

done to exclude urinary reflux. Formalin should not be used in the presence of reflux.

A review of the presentations and management of children with hemorrhagic cystitis after bone marrow transplantation at The Royal Hospital for Sick Children, Glasgow during the period between 1990 and 1997 showed only six children who developed the disease. During this 8-year period 91 children received a bone marrow transplant. The mean age was 12 years (range 5-15 years); all had prophylaxis with hydration and Mesna. The presentation of hemorrhagic cystitis occurred on average 40 days after chemotherapy (range 26-40 days).

Hemorrhagic cystitis was heralded by a period of microscopic hematuria lasting 4-12 days (mean 9 days). Five patients required continuous irrigation, one with normal saline and his condition settled; the other cases failed due to clot retention and catheter blockage. Irrigation with prostaglandin and alum 1\% was tried in two instances but failed to influence the course of the disease. Three children required formal suprapubic vesicostomy with wide stoma; one required temporary urinary diversion and bladder packing and one required emergency cystectomy for massive life-threatening bleeding. Further studies are required to see if earlier intervention during the phase of microscopic hematuria may affect the course of this serious complication. Fibrin glue applied suprapubically while visualizing and insufflating the bladder through a cystoscope achieved hemostasis [81].

\subsubsection{Outcome}

Although hemorrhagic cystitis secondary to cyclophosphamide therapy is usually self-limiting, it can have serious long-term effects especially with regard to bladder fibrosis leading to vesico-ureteric reflux, bladder irritability and incontinence, and ureteric strictures. Renal function may be compromised by the outflow tract obstruction. The long-term problems in some of these patients may require cystectomy or augmentation.

Patients who received more than $50 \mathrm{~g}$ of cyclophosphamide probably require long-term surveillance with blood pressure, urinalysis, and assessment of renal function. In addition there is a $4-7 \%$ increased risk of bladder malignancy [97]. The risks are greatest in those patients receiving both cyclophosphamide and pelvic irradiation without any uroprotection with Mesna. Urine cytology can be used for early detection of new bladder malignancy [109]. Abnormal cytology or evidence of gross or microscopic hematuria requires further investigation with cystoscopy, bladder biopsy, and excretion urogram. 


\subsubsection{Other Conditions Affecting the Genitourinary Tract}

Renal involvement in non-Hodgkins lymphoma is associated with a poor prognostic factor and renal function should be monitored closely. Renal dysfunction caused by direct tumor involvement may complicate therapy and shorten survival [15]. Ureteral obstruction may be caused by L-asparaginase, an effective antileukemia and antilymphoma agent as it is toxic to many organ systems. This could be managed by a double J stent [18].

Children with leukemia may present with acute testicular swellings which can be mistaken for other acute scrotal conditions, e.g., torsion of the testes, epididymo-orchitis. These children have leukemic infiltration of the testes (Fig. 22.9) and a biopsy usually confirms the presence of leukemic cells in the testes. This

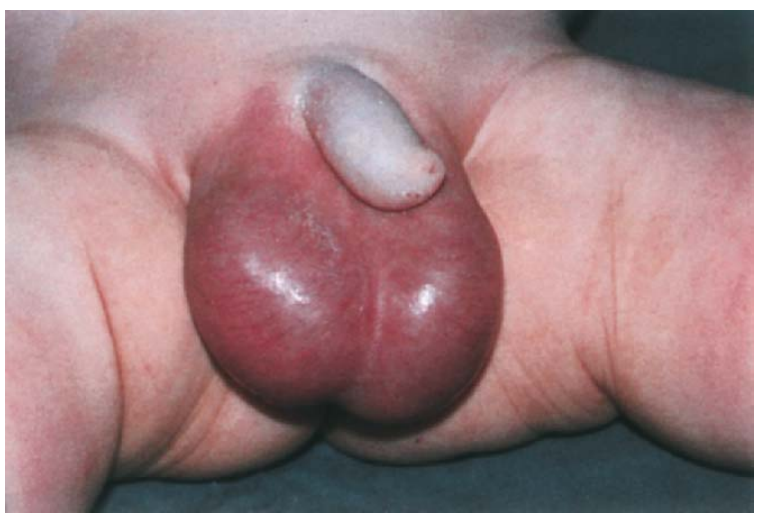

Fig. 22.9 Leukemic infiltration of the testes.

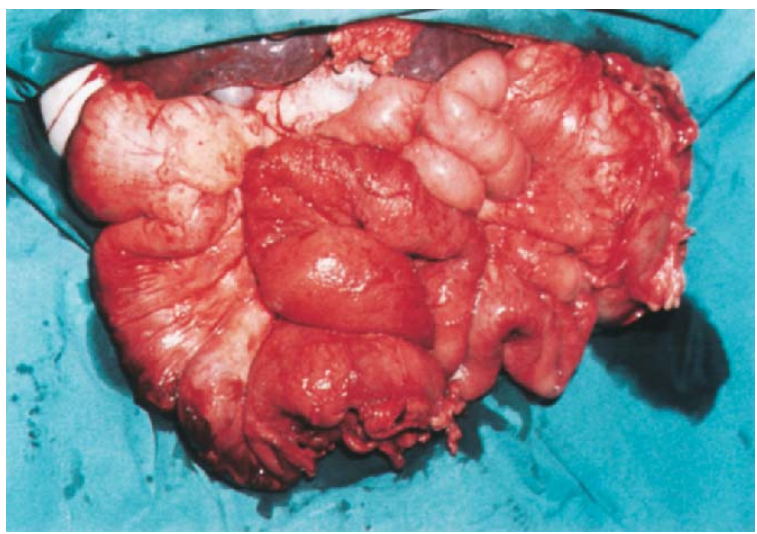

Fig. 22.10 This 4-year-old boy had severe graft-versus-host disease affecting the entire gastrointestinal tract and was managed conservatively for many months. Laparotomy was eventually performed, for persistent intestinal obstruction. Multiple fibrotic strictures were observed and resected. The patient is alive and well 6 years later. is often a presentation in boys who have had treatment for leukemia and have relapsed after their treatment is finished. The testis is considered a "sanctuary site" for tumor persistence and may require irradiation.

\subsection{Intestinal Graft-Versus-Host Disease}

Graft-versus-host disease is one of the major complications of bone marrow transplantation. The concept behind transplantation of allograft bone marrow is that new T lymphocyctes will develop which will recognize the host as "self." However, mature T cells may also be transplanted that have already learned what is "not self" and thus may attack host cells that are covered with "foreign" class I and II major histocompatibility antigens.

\subsubsection{Clinical Features}

Most patients undergoing bone marrow transplantation will develop graft-versus-host disease without specific anti-graft-versus-host disease prophylaxis, at around 2-5 weeks posttransplant. The severity of disease depends on the closeness of the major histocompatibility match, whether the donor marrow has been $\mathrm{T}$ cell depleted, the degree of minor histocompatibility match (related to age, sex, race, etc.), and the type of prophylaxis used.

The skin, followed by the gastrointestinal tract (Fig. 22.10) and liver, are the most commonly affected organs. Cutaneous manifestations include pruritus and a fine erythematous or maculopapular rash. In severe cases blistering and desquamation of the skin may occur. A punch biopsy of the skin is required for definitive diagnosis and grading (Table 22.9) of the histological severity of the graft-versus-host disease. In severe disease, the lung can also be affected (though usually in the more chronic form).

Any area of the alimentary tract from the mouth to the anus can be affected. In one study MacGregor, et al. found that up to $70 \%$ of patients with graft-versus-host disease had some degree of intestinal involvement [59].

The most common manifestations occur in the small bowel and reflect direct effects on the intestine and secondary infections that develop as a consequence of graft-versus-host disease [24, 32, 66, 101, 108]. Symptoms include nausea, vomiting, abdominal cramps, and diarrhea. The diarrhea may be profuse and cause fluid and electrolyte imbalance. Nutritional problems may occur due to malabsorption and a protein-losing enteropathy. Occasionally mucosal casts are passed per rectum. In severe graft-versus-host disease there can be generalized signs of adynamic ileus, 
Table 22.8 Patients at risk of developing acute graft-versushost disease

1. Bone marrow transplant patients [102]

2. Solid organ transplant patients

3. Transfusion of unirradiated blood products in neonates

4. Transfusion of unirradiated blood products in patients receiving immunosuppressive chemoradiotherapy

Table 22.9 Clinical grading of graft-versus-host disease

\begin{tabular}{|c|c|c|c|}
\hline Stage & Skin & $\begin{array}{l}\text { Bilirubin level } \\
\text { (mg/liter) }\end{array}$ & Intestine \\
\hline \multirow[t]{2}{*}{ I } & $\begin{array}{l}\text { Maculopapular } \\
\text { rash }<25 \% \\
\text { of BSA }\end{array}$ & $2-3$ & Diarrhea \\
\hline & & $>500 \mathrm{ml} /$ day & \\
\hline \multirow[t]{2}{*}{ II } & $\begin{array}{l}\text { Maculopapular } \\
\text { rash } 25-50 \% \\
\text { of BSA }\end{array}$ & $3-6$ & Diarrhea \\
\hline & & $>1000 \mathrm{ml} /$ day & \\
\hline \multirow[t]{2}{*}{ III } & $\begin{array}{l}\text { Generalized } \\
\text { erythroderma }\end{array}$ & $6-15$ & Diarrhea \\
\hline & & $>1500 \mathrm{ml} /$ day & \\
\hline IV & $\begin{array}{l}\text { Generalized } \\
\text { erythroderma } \\
\text { with bulla } \\
\text { formation }\end{array}$ & $>15$ & $\begin{array}{l}\text { Severe abdominal } \\
\text { pain, and desqua- } \\
\text { mation with or } \\
\text { without ileus }\end{array}$ \\
\hline
\end{tabular}

BSA, Body surface area. (From [102])

peritoneal irritation, gastrointestinal bleeding, and perforation: this suggests full thickness inflammation with ulceration.

\subsubsection{Investigations}

Investigations include blood tests to assess the severity of electrolyte and serum protein levels with complete blood count and a coagulation profile.

Erect and supine abdominal radiographs may show signs of thumb printing, suggesting mucosal edema; pneumatosis may also be observed as erect chest radiographs (or decubitus abdominal radiographs) may show pneumoperitoneum. Contrast barium enema may show typical signs of gastrointestinal graft-versus-host disease but must be used cautiously in very sick patients because of the risks of perforation [33].
Radiological signs include thickened and effaced mucosal folds, thickened bowel wall and rapid transit. In subacute gastrointestinal graft-versus-host disease the contrast studies show a segmental patchy appearance of ulceration with normal and abnormal areas interspersed [33]. Use of CT scan shows fluid-filled, dilated, poorly opacified bowel loops and characteristic abnormally enhanced, thin mucosa.

Histology of intestinal graft-versus-host disease initially shows necrosis of individual intestinal crypt cells (apoptosis). Progression of disease leads to loss of whole crypts with mucosal denudation and ulceration. In extreme circumstances the entire mucosa may be sloughed off [34].

Endoscopic examination can be very useful. The endoscopic appearance of graft-versus-host disease shows edema, erythema, and frank ulceration but these signs are nonspecific [34]. Mucosal biopsy, however, may be characteristic [101] and can help differentiate graft-versus-host disease from opportunistic infections and other causes of colitis $[65,5]$. Upper gastrointestinal biopsies have a higher yield than biopsies from the colon or rectum. However, as the disease is patchy the most affected area of bowel should be examined. Invasive procedures such as endoscopy or biopsy should be undertaken because the benefits are often life saving and the actual risks of serious complication are relatively low $[5,49,101]$.

\subsubsection{Other Problems in Bone Marrow Transplant Patients}

In addition to problems with the gastrointestinal tract, the surgeon is occasionally consulted for advice and requests for biopsies to help diagnose problems in patients with liver and respiratory problems. We recently reviewed liver and lung biopsies taken from bone marrow transplant patients at the Bristol Royal Hospital for Sick Children with undiagnosed findings such as worsening liver function and increasing respiratory distress. Of eight liver biopsies (seven by Tru-cut and one by open operation) three were related to graftversus-host disease, two were due to viral infection, two were related to transfusion siderosis, and one was an aspergilloma. Two open lung biopsies showed one case of cytomegalovirus pneumonitis and one case of radiation fibrosis. Overall we found the complication rate to be low and a number of unsuspected diagnoses were made that altered future management.39

\subsubsection{Treatment}

Once graft-versus-host disease is documented the treatment is essentially medical with administration of 
high-dose steroid immunosuppression. The prognosis of graft-versus-host disease is worse if skin, gut, and liver are all involved. The only indication for surgical intervention is perforation of the intestine. Severe hemorrhage is best treated by aggressive medical management with correction of clotting abnormalities, platelet transfusion, and endoscopy. The results of surgical resection in the acute phase are universally poor. Once the disease is quiescent the areas of sloughed intestinal mucosa may heal by forming a stricture that may require bowel resection.

\section{References}

1. Alavi S, Arzanian MT, Abbasian MR, Ashena Z (2006) Tumor lysis syndrome in children with non-Hodgkin lymphoma. Pediatr Hematol Oncol 23(1):65-70

2. Amromin GD, Solomon RD (1962) Necrotizing enteropathy. J Am Med Assoc 182:23-29

3. Anderson PE (1993) Neutropenic enterocolitis treated by primary resection with anastomosis in a leukaemic patient receiving chemotherapy. Austr NZ J Surg 63:74-76

4. Angel C, Patrick CC, Lobe T, Rao B, Pui CH (1991) Management of anorectal/perineal infections caused by Pseudomonas aeruginosa in children with malignant diseases. J Pediatr Surg 26:487-492

5. Arul GS, Mullan MH, Cornish J, Oakhill A, Spicer RD (1999) Role of surgical biopsies in the management of bone marrow transplant patients. Medical \& Pediatric Oncology 33:95-98

6. Arul GS, RD Spicer (2001) Ecthyma Gangrenosum - A trap for the unwary. The Annals of the Royal College of Surgeons of England 83, pp 47-48

7. Auldist AW (1976) Wilms' tumor presenting as a varicocele. J Pediatr Surg 11:471-472

8. Avci Z, Alioglu B, Canan O, Szcay F, Celasun B, Sarlattoglu F, Ozbek N (2006) Calcification of the gastric mucosa associated with tumor lysis syndrome in a child with non-Hodgkin lymphoma. Pediatr Hematol Oncol 28(5):307-310

9. Baeksgaard L, Sorensen JB (2003) Acute tumor lysis syndrome in solid tumours - A case report and review of the literature. Cancer Chemother Pharmacol 51:187-192

10. Berg A, Armitage JO, Burns CP (1985) Fournier's gangrene complicating aggressive therapy for hematologic malignancy. Cancer 57:2291-2294

11. Bourque MD, Spigland N, et al. (1989) Esophageal leiomyoma in children: Two case reports and review of the literature. J Pediatr Surg 24:1103-1107

12. Bower RJ, Kiesewetter WB (1997) Colo-colic intussuception due to a hemangioma. J Pediatr Surg 12:777-778

13. Bradbury AW, Barrett S (1997) Surgical aspects of Clostridium difficile colitis. Brit J Surg 84:150-159

14. Browne AF, Katz S, Miser J, Boles ET (1983) Blue rubber bleb nevi as a cause of intussusception. J Pediatr Surg 18:7-9

15. Buyukpamukcu M, Caran A, Aydin B, Kale G, Akata D, Yalcin B, Akyuz C, Kutluk T (2005) Renal invovlement in non-Hodgkin's lymphoma and its prognostic effect in childhood. Nephron Clin Pract 100(3):c86-91
16. Caty MG, Oldham KT, Prochownik EV (1990) Embryonal rhabdomyosarcoma of the ampulla of Vater with long term survival following pancreaticoduodenectomy. J Pediatr Surg 25:1256-1260

17. Chang WL, Griffith KM (1991) Solitary intestinal fibromatosis: A rare cause of intestinal obstruction in neonates and infants. J Pediatr Surg 26:1406-1408

18. Chen CH, Lu MY, Lin KH, Peng SF, Jou ST (2004) Ureteral obstruction casued by L-asparaginase-induced pancreatitis in a child with acute lymphoblastic leukemia. J Formos Med Assoc 103(5):380-384

19. Coggins PR, Ravdin RG, Eisman SH (1959) Clinical pharmacology and preliminary evaluation of cytoxan (cyclophosphamide). Cancer Chemo Rep 3:9

20. De Kraker J (1998) Arteriovenous fistula: A complication following renal biopsy of suspected bilateral Wilms' tumor [letter] Med Paediatr Oncol 30:125

21. Donahue LA, Frank IN (1989) Intravesical formalin for haemorrhagic cystitis: Analysis of therapy. J Urol 141:809812

22. Donaldson SS, Jundt S, Ricour C, Sarrazin D, Lemerle J, Schweisguth O (1975) Radiation enteritis in children. A retrospective review, clinicopathologic correlation, and dietary management. Cancer 35:1167-1178

23. Donnelly LF (1996) CT imaging of immunocompromised children with acute abdominal symptoms. Am J Roentgenol 167:911-913

24. Donnelly LF, Morris CL (1996) Acute graft-versus-host disease in children: Abdominal CT findings. Radiology 199:265-268

25. Eichelberger MR, Chatten J, Bruce DA (1981) Acute pancreatitis and increased intracranial pressure. J Pediatr Surg 16:562-570

26. Ein SH, Stephens CA, Shandling B, Filler RM (1986) Intussusception due to lymphoma. J Pediatr Surg 21:786-788

27. Einhorn M (1961) Temporary remission in acute leukemia after an attack of 'acute appendicitis'. J Am Med Assoc 175:1006-1008

28. El-Zimaity M, Saliba R, Chan K, Shahjahan M, Carrasco A, Khorshid O, Caldera H, Couriel D, Girait S, Khouri I, Ippoliti C, Champlin R, de Lima M (2004) Hemorrhagic cystitis after allogeneic hematoppietic stem cell transplantation; Donor type matters. Blood 103(12):4674-4680

29. Exelby PR, Ghandchi A, Lansigan N, Schwartz I (1975) Management of the acute abdomen in children with leukaemia. Cancer 35:826-829

30. Fasano R, Kent P, Valentino L (2005) Superior vena cava thrombus treated with low-dose, peripherally administered recombinant tissue plasminogen activator in a child: Case report and review of the literature. J Pediatr Hematol Oncol 27(12):637-638

31. Fergie JE, Patrick CC, Lott L (1991) Pseudomonas aeruginosa cellulitis and ecthyma gangrenosum in immunocompromised children. Pediatr Infect Dis J 10:496-499

32. Ferrara UL, Deeg HJ 1991) Graft versus host disease. New Engl J Med 324:667-674

33. Fisk JD, Shulman HM, Greening RR, et al. (1981) Gastrointestinal radiographic features of human graft-versus-host disease. Am J Roentgenol 136:329-336 
34. Galati JS, Wisecarver JL, Quigley EMM (1993) Inflammatory polyps as a manifestation of intestinal graft versus host disease. Gastrointest Endosc 39:719-722

35. Galland RB, Spencer J (1985) The natural history of clinically established radiation enteritis. Lancet i:1257-1258

36. Gandy W, Greenberg BR (1983) Successful medical management of neutropaenic enterocolitis. Cancer 51:15511555

37. Garat JM, Martinez E, Aragona F (1985) Open instillation of formalin for cyclophosphamide-induced hemorrhagic cystitis in a child. Eur J Urol 11:192-194

38. Garrington T, Ben Sard D, Ingram JD, et al. (1998) Successful management with ocreotide of a child with L-asparagenase induced hemorrhagic pancreatitis. Med Paediatr Oncol 30:106-109

39. Gavan DR, Hendry GM (1994) Colonic complication of acute lymphoblastic leukaemia. Brit J Radiol 67:449-452

40. Gibbons MD, Duckett JW (1979) Neuroblastoma masquerading as congenital ureteropelvic obstruction. J Pediatr Surg 14:420-422

41. Glenn J, Cotton D, Wesley R, Pizzo P (1988) Anorectal infections in patients with malignant diseases. Rev Infect Dis 10:42-52

42. Godzinski J, Weirich A, Tournade MF, et al. (1996) Primary nephrectomy for emergency in SIOP-9 Wilms' tumor patients. Med Pediatr Oncol 27:219

43. Goodman ZD, Boitnott JK, Yardley JH (1979) Perforation of the colon associated with cytomegalovirus infection. Dig Dis Sci 24:376-380

44. Grewal H, Guillem JG, Quan SH, Enker WE, Cohen AM (1994) Anorectal disease in neutropenic leukemic patients. Operative vs. nonoperative management. Dis Colon Rectum 37:1095-1099

45. Gweon P, Shanberg A (1997) Treatment of cyclophosphamide induced hemorrhagic cystitis with neodymium:YAG laser in pediatric patients. J Urol 157:2301-2302

46. Haddad GK, Grodsinsky C, Allen H (1983) The spectrum of radiation enteritis. Surgical considerations. Dis Colon Rectum 26:590-594

47. Haley T, Dimler M, Hollier P (1986) Gastric teratoma with gastrointestinal bleeding. J Pediatr Surg 21:949-950

48. Kaste SC, Flynn PM, Furman WL (1997) Acute lymphoblastic leukemia presenting with typhlitis. Med Pediatr Oncol 28:209-212

49. Kaw M, Przepiorka D, Sekas G (1993) Infectious complications of endoscopic procedures in bone marrow transplant recipients. Digest Dis Sci 38:71-74

50. Kelly CP, Pothoulakis C, La Mont JT (1994) Clostridium difficile colitis. New Engl JMed 330:257-262

51. Kerdudo C, Aerts I, Fattet S, Chevret L, Pacquement H, Doz F, Michon J, Garabedian M, Orback D (2005) Hypercalcemia and childhood cancer: A 7-year experience. Pediatr Hematol Oncol 27(1):23-27

52. Kirchner SG, Horev G (1985) Diagnostic imaging in children with acute chest and abdominal disorders. Pediatr Clin North Am 32:1363-1382

53. Kumar A, Aggarwal S (1990) The sonographic appearance of cyclophosphamide-induced acute haemorrhagic cystitis. Clin Radiol 41:289-290
54. Laszlo D, Bosi A, Guidi S, et al. (1995) Prostaglandin E2 bladder instillation for the treatment of hemorrhagic cystitis after allogeneic bone marrow transplantation. Haematologica 80:421-425

55. Lawrence HJ, Simone J, Aur RJA (1975) Cyclophophamide-induced hemorrhagic cystitis in children with leukemia. Cancer 36:1572-1576

56. Levine LA, Jarrard DF (1993) Treatment of cyclophosphamide-induced hemorrhagic cystitis with intravesical carboprost tromethamine. J Urol 149:719-723

57. Levine LA, Richie JP (1989) Urological complications of cyclophosphamide. J Urol 141:1063-1069

58. Liu YK, Harty JI, Steinbock GS, Holt HA Jr, Goldstein DH, Amin M (1990) Treatment of radiation or cyclophosphamide induced hemorrhagic cystitis using conjugated estrogen. J Urol 144:41-43

59. MacGregor GI, Shepherd JD, Philips GL (1988) Acute graft versus host disease of the intestine. A surgical perspective. Am J Surg 155:680-682

60. Mallory A, Kern F Jr (1980) Drug-induced pancreatitis: A critical review. Gastroenterology 78:813-820

61. Massicotte P, Mitchell L (2006) Thromboprophylaxis of central venous lines in children with cancer: The first steps taken on the long road ahead. Acta Paediatr 95(9):10491052

62. Matthew R, Christoper O, Pillippa S (2006) Severe malignancy-associated hypercalcemia in dysgerminoma. Pediatr Blood Cancer 15:621-623

63. McCarville MB, Adelman CS, Li C, Xiong X, Furman WL, Razzouk BI, Pui CH, Sandlund JT (2005) Typhilitis in childhood cancer. Cancer 104(2):380-387

64. McCarville MB, Thompson J, Li C, Adelman CS, Lee MO, Alsammarae D, May MV, Jones SC, Rao BN, Sandlund JT (2004) Significance of appendiceal thickening in association with typhilitis in pediatric oncology patients. Pediatr Radiol 34(3):245-249

65. McDonald GB, Sharma P, Hackman RC, Meyers JD, Thomas ED (1985) Esophageal infections in immunosuppressed patients after marrow transplantation. Gastroenterology 88:1111-1117

66. McDonald GB, Shulman HM, Sullivan KM, Spencer GD (1986) Intestinal and hepatic complications of human bone marrow transplantation. Part II. Gastroenterology 90:770784

67. McNamara MJ, Chalmers AG, Morgan M, Smith SEW (1986) Typhilitis in acute childhood leukemia: Radiological features. Clin Radiol 37:83-86

68. Mendelson RM, Nolan DJ (1985) The radiological features of chronic radiation enteritis. Clin Radiol 36:141-148

69. Meric F, Hirschl RB, Mahboubi S, et al. (1994) Prevention of radiation enteritis in children, using a pelvic mesh sling. J Pediatr Surg 29:917-922

70. Merine DS, Fishman EK, Jones B, Nussbaum AR, Simmons T (1987) Right lower quadrant pain in the immunocompromised patient: CT findings in 10 cases. Am J Radiol 149:1177-1179

71. Miller SD, Andrassey RJ (2003) Complications in paediatric surgical oncology. J Am Coll Surg 197 (5):832-837

72. Moir CR, Scudamore CH, Benny WB (1986) Typhlitis: Selective surgical management. Am J Surg 151:563-566 
73. Mukamel E, Lupu A, deKernion JB (1986) Alum irrigation for severe bladder haemorrhage. J Urol 147:697-699

74. Nguyen DL, Wilson DA, Engelman ED, Sexauer CL, Nitschke R (1987) Serial sonograms to detect pancreatitis in children receiving L-asparaginase. Southern Med J 80:1133-1136

75. North JH Jr, Weber TK, Rodriguez-Bigas MA, Meropol NJ, Petrelli NJ (1996) The management of infectious and noninfectious anorectal complications in patients with leukemia. J Am Coll Surg 183:322-328

76. Ojala AE, Lanning FP, Lanning BM (1997) Abdominal ultrasound findings during and after treatment of childhood acute lymphoblastic leukemia. Med Pediatr Oncol 29:266271

77. Okaneya T, Kontani K, Komiyama I, Takezaki T (1993) Severe cyclophosphamide-induced hemorrhagic cystitis successfully treated by total cystectomy with ileal neobladder substitution: A case report. J Urol 150:1909-1910

78. Paletta CE, Dehghan K (1994) Compartment syndrome in children. Ann Plast Surg 32:141-144

79. Pession A, Barbieri E (2005) Treatment and prevention of tumor lysis syndrome in children. Experience of Associazione Italiana Ematologia Oncologia Pediatrica Contrib Nephrol 147:80-92

80. Pestalozzi BC, Sotos GA, Choyke PL, Fisherman JS, Cowan KH, O'Shaughnessy JA (1993) Typhlitis resulting from treatment with taxol and doxorubicin in patients with metastatic breast cancer. Cancer 71:1797-1800

81. Purves JT, Graham ML, Ramakumar S (2005) Application of fibrin glue to damaged bladder mucosa in a case of BK viral hemorrhagic systitis. Urology 66(3):641-643

82. Redman JF, Kletzel M (1994) Cutaneous vesicostomy with direct intravesical application of formalin: Management of severe vesical hemorrhage resulting from high dose cyclophosphamide in boys. J Urol 151:1048-1050

83. Riker WL, Goldstein RI (1968) Malignant tumors of childhood masquerading as acute surgical conditions. J Pediatr Surg 3:580-583

84. Ritchey ML, Kelalis PP, Breslow N, et al. (1992) Surgical complications after nephrectomy for Wilms' tumor. Surg Gynec Obstet 175:507-514

85. Roberts JP, Atwell JD (1989) Testicular enlargement as a presenting feature of monocytic leukemia in an infant. J Pediatr Surg 24:1306-1307

86. Roy J, Snover D, Weisdorf S, Mulvahill A, Filipovich A, Weisdorf D (1991) Simultaneous upper and lower endoscopic biopsy in the diagnosis of intestinal graft-versus-host disease. Transplantation 51:642-646

87. Shamberger RC, Weinstein HJ, Delorey MJ, Levey RH (1986) Medical and surgical management of typhlitis in children with acute non-lymphocytic (myelogenous) leukaemia. Cancer 57:603-609

88. Shivshanker K, Chu DZ, Stroehlein JR, Nelson RS (1983) Gastrointestinal hemorrhage in the cancer patient. Gastrointest Endosc 29:273-275

89. Shurafa M, Shumaker E, Cronin S (1987) Prostaglandin F2-alpha bladder irrigation for control of intractable cyclophosphamide-induced hemorrhagic cystitis. J Urol 137:1230-1231
90. Singh TN, Devi KM, Devi KS (2005) Ecthyma gangrenosium: A rare cutaneous maifestation caused by pseudomonas aeruginosa without bacteraemia in a leukaemic patient - A case report. Indian J Med Microbiol 23(4):262-263

91. Skibber JM, Matter GJ, Pizzo PA, Lotze MT (1987) Right lower quadrant pain in young patients with leukaemia. Ann Surg 206:711-715

92. Sloas MM, Flynn PM, Kaste SC, Patrick CC (1993) Typhlitis in children with cancer: A 30-year experience. Clin Infect Dis 17:484-490

93. Spicer RD, Cywes S (1988) Pancreatitis in childhood. Pediatr Surg Int 3:33-36

94. Spirnak JP, Resnick MI, Hampel N, Persky L (1984) Fournier's gangrene: Report of 20 patients. J Urol 131:289291

95. Stillwell TJ, Benson RC Jr (1988) Cyclophosphamide-induced hemorrhagic cystitis: A review of 100 patients. Cancer 61:451-457

96. Stone MM, Weinberg B, Beck AR, et al. (1986) Colonic obstruction in a child with von Recklinghausen's neurofibromatosis. J Pediatr Surg 21:741-743

97. Strand WR (1996) Haemorrhagic cystitis in children. Dialog Pediatr Urol 19:1-10

98. Surana R, Quinn FM, Guiney EJ (1992) Intussusception as a cause of postoperative intestinal obstruction in children. Brit J Surg 79:1200

99. Sussman SJ, Schiller RP, Shashikumar VL (1978) Fournier's syndrome. Am J Dis Child 132:1189-1191

100. Temeck BK, Venzon DJ, Moskaluk CA, Pass HI (1994) Thoracotomy for pulmonary mycoses in non-HIV-immunosuppressed patients. Ann Thorac Surg 58:333-338

101. Terdiman JP, Linker CA, Ries CA, Damon LE, Rugo HS, Ostroff JW (1996) The role of endoscopic evaluation in patients with suspected intestinal graft-versus-host disease after allogeneic bone-marrow transplantation. Endoscopy 28:680-685

102. Thomas ED, Storb R, Clift RA, et al. (1975) Bone marrow transplantation New Engl J Med 90:895-902

103. Top PC, Tissing WJ, Kuiper JW, Pieters R, van Eijck CH (2005) L-asparaginase-induced severe necrotizing pancreatitis successfully treated with percutaneous drainage. Pediatr Blood Cancer 44(1):95-97

104. Trivedi CD, Pitchumoni CS (2005) Drug-induced pancreatisis; An update. J Clin Gastroenterol 39(8):709-716

105. Tsakayannis DE, Kozakewich HP, Lillehei CW (1996) Acalculous cholecystitis in children. J Pediatr Surg 31:127-131

106. Tunell WP (1976) Haemangioendothelioma of the pancreas obstructing the common bile duct and duodenum. J Pediatr Surg 11:827-830

107. Turkeri LN, Lum LG, Uberti JP, et al. (1995) Prevention of hemorrhagic cystitis following allogeneic bone marrow transplant preparative regimens with cyclophosphamide and busulfan: Role of continuous bladder irrigation. J Urol 153:637-640

108. van Bekkum DW (1991) What is graft versus host disease? Bone Marrow Transpl 7(Suppl 2):110-111

109. Van Dyk OJ, Posso M (1975) Congenital leiomyomatous tumor in a newborn simulating jejunal atresia. J Pediatr Surg 10:139-141 
110. Varki AP, Armitage JO, Feagler JR (1978) Typhilitis in acute leukaemia. Cancer 43:695-697

111. Wagner ML, Rosenberg HS, Fernbach DJ, Singleton EB (1970) Typhlitis, a complication of leukemia in childhood. Am J Radiol 109:341-350

112. Walker-Renard PB, Vaughan LM, Sahn SA (1994) Chemical pleurodesis for malignant pleural effusions. Ann Int Med 120:56-64

113. Wallace AM, Newman K (1991) Successful closure of intestinal fistulae in an infant using the somatostatin analogue SMS 201-995. J Pediatr Surg 26:1097-1100

114. Wang LY, Shih LY, Chang H, Jou ST, Lin KH, Yeh TC, Lin SF, Liang DC (2006) Recombinant urate oxidase (rasburicase) for the prevention and treatment of tumor lysis syndrome in patients with hematologic malignancies. Acta Maematol 115(1-2):35-38

115. Wayne ER, Campbell JB, Kosloske AM, Burrington JD (1976) Intussusception in the older child - Suspect lymphosarcoma. J Pediatr Surg 11:789-794

116. Weinberger M, Hollingsworth H, Feuerstein IM, Young NS, Pizzo PA (1993) Successful surgical management of neutropenic enterocolitis in two patients with severe aplastic anemia. Case reports and review of the literature. Arch Int Med 153:107-113
117. Wellwood JM, Jackson BT (1973) The intestinal complications of radiotherapy. Brit J Surg 60:814-818

118. Widburger R, Hollwarth ME (1989) Bronchoadenoma in childhood. Paediatr Surg Int 4:373-380

119. Williams BJ, Mulvihill DM, Pettus BJ, Brothers R, Costello P, Schoepf UJ (2006) Pediatric superior vena cava syndrome: Assessment at low radiation dose 64-slice CT angiography. Thorac Imaging 21(2):71-72

120. Wobbes T, Verschueren RC, Lubbers EJ, Jansen W, Paping $\mathrm{RH}$ (1984) Surgical aspects of radiation enteritis of the small bowel. Dis Colon Rectum 27:89-92

121. Yim AP, Low JM, Ng SK, Ho JK, Liu KK (1995) Video-assisted thoracoscopic surgery in the paediatric population. J Paediatr Child Health 31:192-196

122. Yokoyama T, Kondo H, Yokota T, et al. (1997) Colonoscopy for frank bloody stools associated with cancer chemotherapy. Jpn J Clin Oncol 27:111-114

123. Young G, Shende A (1998) Use of pamidronate in the management of acute cancer-related hyercalcemia in children. Med Pediatr Oncol 30:117-122 